\title{
Numerical modelling of three-dimensional wave-current interactions in complex environment: Application to Alderney Race
}

\author{
Bennis Anne-Claire ${ }^{1,{ }^{*}}$, Furgerot Lucille ${ }^{2}$, Bailly Du Bois Pascal ${ }^{3}$, Dumas Franck ${ }^{4}$, Odaka Tina ${ }^{5}$, \\ Lathuilière Cyril ${ }^{4}$, Filipot Jean-Francois ${ }^{6}$
}

\author{
${ }^{1}$ Normandie Univ., UNICAEN, CNRS, UNIROUEN, Morphodynamique Continentale et Côtière (M2C), \\ Caen, France \\ 2 Normandie Univ., UNICAEN, Laboratoire Universitaires des Sciences Appliquées de Cherbourg \\ (LUSAC), Cherbourg en Cotentin, France \\ ${ }^{3}$ IRSN, Laboratoire de Radioecologie de Cherbourg (LRC), Cherbourg en Cotentin, France \\ ${ }^{4}$ Shom, HOM/REC, Brest, France \\ ${ }^{5}$ University of Brest, CNRS, IRD, Ifremer, Laboratoire d'Océanographie Physique et Spatiale (LOPS), \\ IUEM, Brest, France \\ ${ }^{6}$ France Energies Marines (FEM), Plouzané, France
}

*Corresponding author : Anne-Claire Bennis, email address : ac.bennis@unicaen.fr

\begin{abstract}
:
Modelling three-dimensional wave-current-turbulence interactions in extreme tidal environments is still challenging and necessary for the development of the tidal industry, particularly for the dimensioning of tidal converters. Following this objective, we focus our study on the most energetic tidal site in Western Europe, the Alderney Race (France). Due to the strong tidal current at this location, wave-current interactions were poorly studied by the past and often neglected. We propose to assess how they impact the Alderney Race hydrodynamic by the use of numerical modelling and in-situ measurements. In this study, the following wave-current interactions were observed: (i) Stokes drift effects inducing an increase/decrease in the current depending on the angle between waves and current, with a maximum influence near the surface, (ii) wave enhancement of the bottom friction reducing the tidal current, (iii) refraction of waves by the current, generating changes in waves directions, and (iv) wave breaking ascribed to tidal current, increasing the turbulent mixing. A non-stationary time delay, varying within a same tidal cycle, was noted, which is reduced by including the local wind effects and by adjusting the bottom stress formulation. This study shows that wave-current interactions play a non-negligible role in Alderney Race although the strong tidal current and that they need to consider by the tidal industry.
\end{abstract}




\section{Introduction}

Marine renewable energies represent an alternative to fossil energies, which contribute to climate change. Ocean energy from tidal currents has a great potential throughout the world, because the currents are reliable and predictable and could be strong enough for industrial exploitation (e.g. Lynn 2013). In addition, the visual impact of tidal stream devices are limited in comparison to offshore wind farms or some wave energy converters. However, installation and maintenance of tidal converters are more complex than for other technologies due to the particular hydrodynamic conditions of tidal sites. Ocean tidal energy is considered economically feasible for water depths shallower than 50 meters and a flow velocity larger than $2.5 \mathrm{~m} / \mathrm{s}$ (e.g. Lewis et al. 2015). A key point for the development of tidal energy is resource characterisation, which includes tidal site selection, possible modifications of the hydro-sedimentary environment induced by turbines and the impact of sediment transport on devices.

The most energetic tidal site in Western Europe is the Alderney Race, located in France, between La Hague Cape and Alderney Island, with tidal current reaching $5 \mathrm{~m} / \mathrm{s}$ during spring tide (e.g. Bahaj and Myers 2004). Field measurements by velocity profilers were conducted in the past to estimate the hydrodynamic resources of the Alderney Race (e.g. Thiebault et al. 2019), but complex conditions generally led to loss or breakage of scientific devices making it very difficult to complete the measurements. Radio-oceanography, with High Frequency (HF) or/and Very High Frequency (VHF) and/or X-band radars, is a relevant option to obtain real-time spatialised measurements of flow velocity and ocean wave characteristics (e.g. Lopez et al. 2019). Numerical modelling is a useful alternative to estimate tidal resources. Because the circulation is primarily driven by astronomical tides, it can be computed with a barotropic model forced by tidal components at its open boundaries (Thiebot et al. 2015). The design of tidal energy converters, however, requires knowledge of the vertical structure of flow velocity in order to assess material fatigue issues and correct assessment of the energy production. Vertical profile depends on tide, as well as on ocean waves, marine turbulence and hydrodynamic interactions. A three-dimensional (3D) fully-coupled wave-current model with an accurate modelling of turbulent mixing is therefore required.

Most of sites that are suitable for tidal converters, including Alderney Race in Normandy (France) and Fromveur in Brittany (France), are influenced by surface waves, that modify the vertical shear of ocean velocity. Major modifications occur near the surface and up to a depth of about one half wavelength, but also near the bottom mainly within the wave and current bottom boundary layers (e.g. Nielsen 1992). Near-surface, ocean velocity may be reduced or accelerated depending on the angle between wave direction and tidal current due to Stokes drift effects (e.g. Kemp and Simons 1983, 1982; Groeneweg and Klopman 1998). Ocean waves also change the vertical shear of the turbulent quantities because of wave-enhancement of 
turbulence in the bottom boundary layer and near the surface (e.g Grant and Madsen 1979; Burchard 2001). Grant and Madsen (1979) proposed a time-invariant two-layer turbulent model to take into account the wave effects on the turbulence level near and beyond the bottom. Following the same idea, many studies have proposed different formulations for the time-invariant turbulent eddy viscosity (e.g. Christoffersen and Jonsson 1985; Sleath 1991). In the upper ocean, changes in turbulence levels due to waves are mainly caused by wave breaking and Langmuirs circulations (e.g. Agrawal et al. 1992; Craik and Leibovich 1976).

Lewis et al. (2017) and Thiebault and Sentchev (2017) explain that the vertical shear of the ocean velocity in tidal areas follows a power law in some cases. However, Lewis et al. (2017) highlight high variability in vertical shear, showing the necessity to improve our understanding of the hydrodynamic processes that cause this variability. Togneri et al. (2017) explain that the well-known turbulent closure $k-\epsilon$ without modifications to include wave effects fails to reproduce the vertical structure of turbulent quantities. They observe an underestimate of turbulent kinetic energy while turbulent dissipation is overestimated. Guillou et al. (2016), Lewis et al. (2014) and Hashemi et al. (2015) have studied the influence of surface waves on the tidal energy estimate. On the whole, they found $10-20 \%$ variation due to waves, depending on the angle between the tidal current and surface waves. However, these earlier studies are idealised : Guillou et al. (2016) used three-dimensional radiation stresses that are constant over the depth, because they were in shallow waters. In addition, in the latter study, the real case of the Iroise Sea is treated but vertical shear of the ocean flow is not discussed. Lewis et al. (2014) employ the COASWT model (Warner et al. 2010) with three-dimensional radiation stresses of Mellor (2015), which are debated by Ardhuin et al. (2017) and Mellor (2017), and study an idealised case of a 3D wave-induced flow propagating over a seamount. Hashemi et al. (2015) simulate the real case of the tidal site off the northwestern coast of Anglesey Island (Wales, UK), with the inclusion of wave effects, but these simulations are two-dimensional (depth-integrated). Therefore, 3D effects were not taken into account.

Ocean waves also influence the bottom friction because they modify the turbulence level near the bottom, particularly inside the wave bottom boundary layer. Grant and Madsen (1979) have conceptualised these processes by a large apparent roughness. Many laboratory and in-situ measurements (e.g Mathisen and Madsen 1996b,a) have supported this concept. Mathisen and Madsen (1999) added the streaming effects to the original form of the apparent roughness model established by Grant and Madsen (1979). Parameterised approaches based on the outputs of these studies have also been developed to formulate the bottom shear stress under waves and current action (e.g. Soulsby et al. 1993; Holmedal et al. 2000) and are widely used by the scientific community when numerical models are not able to explicitly resolve these interactions. 
We propose to extend the existing studies by performing realistic 3D simulations with a fully-coupled wave-current model (Bennis et al. 2011, 2014, 2016, 2018) in order to understand, how ocean waves and tidal current interact in Alderney Race. The data and methods are described in Section 2 as follows : 2a. Study site and in-situ data, 2b. Numerical modelling, 2c. Details on coupling procedure and set-up, and 2d. Description of the numerical experiments. Results are shown and discussed in Section 3 which is divided into four parts: 3a. Tidal elevation, 3b. Sea states, 3c. Time series of the tidal stream velocity, and 3d. Vertical structure of the tidal stream velocity. Conclusions are drawn in Section 4.

\section{Data and Methods}

\section{a. Study Site and Data Collection}

Alderney Race is located inside the English Channel (hereinafter EC) between the Alderney Island and La Hague Cape along the French coast, with a depth of 25-65 m (see Figure 1a). Due to the proximity of the Cherbourg harbour and its facilities, that facilitates marine operations, companies are interested in installing of marine currents turbines (MCTs) to produce electricity from tidal current. Alderney Race is a mega-tidal environment (e.g. Dauvin 2015), with a mean spring tidal range variyng from 6 to $11 \mathrm{~m}$ from the north to the south of La Hague Cape (about $5 \mathrm{~km}$ between Anse de Saint Martin : 49 $42^{\prime} 30^{\prime \prime} \mathrm{N} / 1^{\circ} 53^{\prime} 0^{\prime \prime} \mathrm{W}$ and Herqueville : $49^{\circ} 40^{\prime} 06^{\prime \prime} \mathrm{N} / 1^{\circ} 52^{\prime} 34^{\prime \prime} \mathrm{W}$ ) and with a strong tidal asymmetry due to the interactions between tidal flow and bathymetry (see Figure 1b). The particular geometry of the Alderney Race, with the short distance, around $12 \mathrm{kms}$, between Alderney Island and La Hague Cape, generates a channel effect that accelerates the tidal flow up to $5 \mathrm{~m} / \mathrm{s}$ during spring tides. The maximum mean potentiel power is estimated to be $5.1 \mathrm{GW}$ (Coles et al. 2017). For comparison, this represents half of the French tidal resource (Bahaj and Myers 2004) and is $35 \%$ higher than the potential power of Pentland Firth, the best tidal site in United Kingdom.

Swells from the Altlantic Ocean propagate through the EC, mainly in the western part because they are often stopped by the Cotentin peninsula. Alderney Race, located west of this peninsula, though protected by the Alderney Island, is influenced by swells (e.g. Lopez et al. 2018). The dominant winds in La Hague Cape are south-west or west, with wind velocity stronger than $16 \mathrm{~m} / \mathrm{s}$ about 130 days per year according to the French Weather Service (Météo-France). Thus, Alderney Race sea states are often complex, with superposition of swells and wind-seas. Maisondieu (2016) performed statistical analyses based on the HOMERE database (Boudiere et al. 2013) for the period between 2003 and 2012. The results were : i) about $40 \%$ of sea states had at least 3 swells, ii) about $30 \%$ of sea states had at least 2 swells and 1 wind-sea, and iii) about $20 \%$ of sea states have at least 1 swell and 1 
wind-sea. Furthermore, a chaotic sea was observed when the tidal current and wind directions were opposite, with wave heights of about $4 \mathrm{~m}$ and wavelengths shorter than 50 metres. Complex sea states also occured and were recorded during the HYD2M experiments, with significant wave heights of about $8 \mathrm{~m}$. Wave breaking is often observed in Alderney Race due to the interactions between waves and the tidal current, leading to the French name 'Raz Blanchard' (In English : 'White Race', named for the frequent white caps in this area). High energy marine turbulent structures are present in Alderney Race because of the very rough nature of the seabed, which leads to the ejection of turbulent cells from the bottom to the surface (Mercier 2019). These structures, a few tens of meters in length, are 3D and visible to the naked eye. They interact with the tidal current and ocean waves. Moreover, the bathymetry is very uneven with features and faults acting as several metre height barriers to the flow (Furgerot et al. 2019). The bottom sedimentology is strongly heterogeneous with sand, pebbles and large rocks (e.g. Larsonneur et al. 1982; Foveau et al. 2017; Furgerot et al. 2019).

ADCP data were collected by the HYD2M consortium (ADCP) in 2017 (see Figure 1a, yellow cross), using a bottom-mounted $500 \mathrm{kH}_{\mathrm{z}}$ Teledyne RDI Sentinel V50. ADCP was located at $49^{\circ} 40^{\prime} 50.00^{\prime \prime} \mathrm{N} / 2^{\circ} 01^{\prime} 46.44^{\prime \prime} \mathrm{W}$. The estimated mean depth was about $35 \mathrm{~m}$. The bin size was $1 \mathrm{~m}$ and the lowest cell was $2 \mathrm{~m}$ above the seabed. ADCP data were collected from 14 October 2017 to 26 February 2018, but only days in the period of 21 to 25 November 2017 are considered here. ADCP recorded ocean wave characteristics in addition to measurements of vertical profile of the three components of the flow velocity. All ADCP data were 15 min-averaged. This means that high frequency variations, particularly due to turbulence, were not taken into account in this study, but were presented in Furgerot et al. (2018). Data from Met-Office wave buoys (62103 and 62027), available on EMODnet platform (http ://www.emodnet.eu), were also used to validate the wave model, but comparison plots are not shown here. The simulated mean sea level was tested against measurements of Shom tidal gauges installed in Cherbourg (TG1, recordings from 1943 to now) and Dièlette (TG2, recordings from 2015 to now). Data are downloadable via the datashom portal (https ://data.shom.fr). Tidal gauge locations are marked in black on Figure 1a. Wind data were collected by Goury Semaphore, that is located $7 \mathrm{~km}$ apart ADCP point, at 10 meters above ground level.

The studied time period is representative of typical conditions in Alderney Race, except for extreme events. The met-oceanic conditions were : i) a tidal range between 4 and $7 \mathrm{~m}$, ii) a tidal current varying from $0.2 \mathrm{~m} / \mathrm{s}$ to $3 \mathrm{~m} / \mathrm{s}$, iii) a significant wave height ranging from $0.5 \mathrm{~m}-4.5 \mathrm{~m}$ (with wind-waves and swells), and iv) a wind speed less than $18 \mathrm{~m} / \mathrm{s}$. 
a)

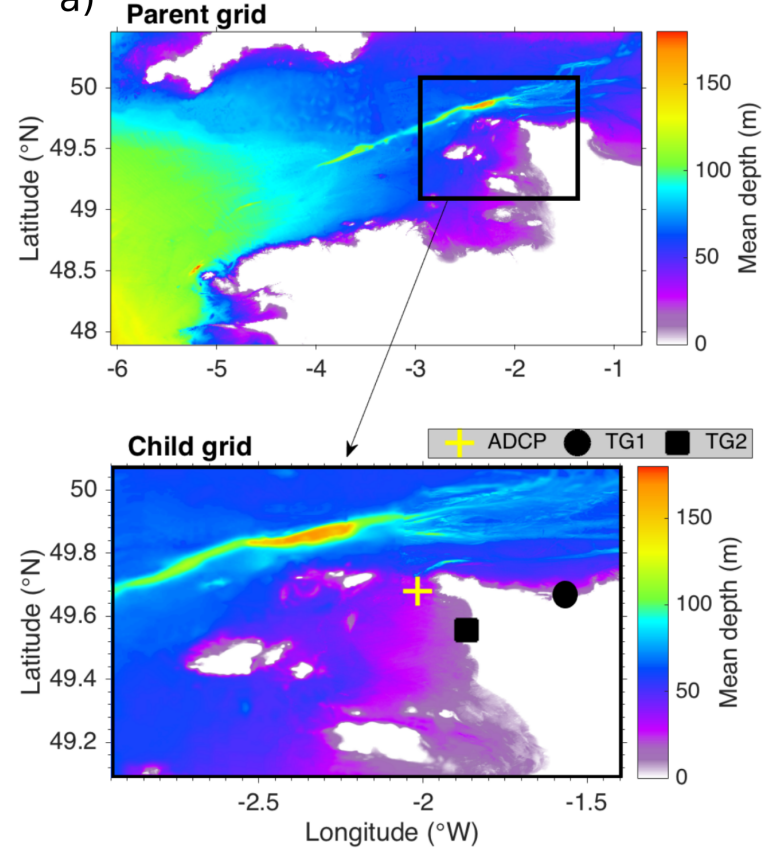

b)

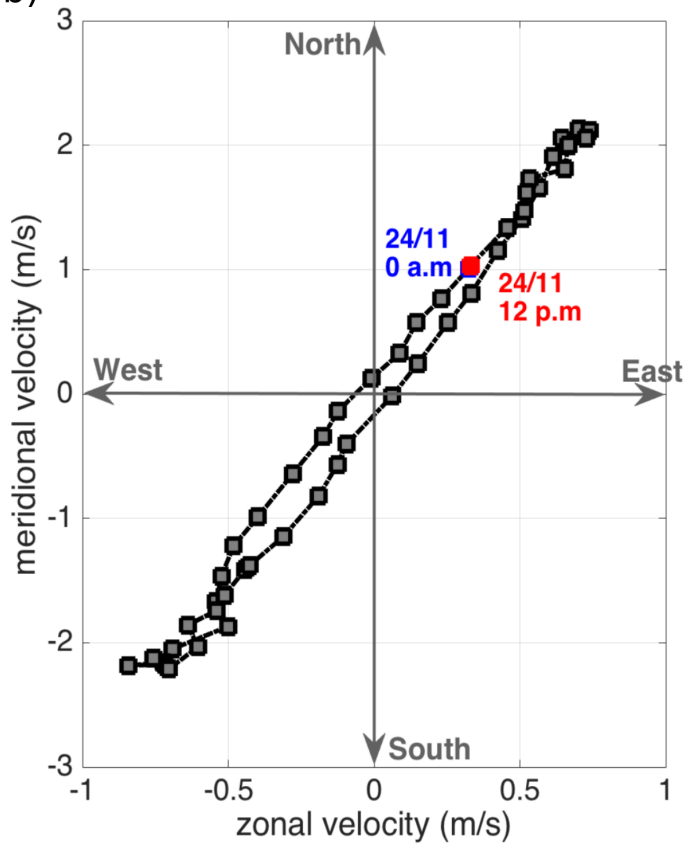

Figure 1: (a) ADCP (yellow cross) and tidal gauges (TG1 and TG2 in black circle and square, respectively) over the mean depth (colour scale). (b) Current hodograph for a 12-hour time period on 24 November 2017 between 0 a.m. (blue square) and 12 p.m. (red square).

\section{b. Numerical Modelling Strategy}

Our modelling system couples a 3D ocean model, MARS3D v10 (Lazure and Dumas 2008), and the spectral wave model, WAVEWATCH III v4.08 (hereinafter WW3, Tolman and al. 2014). The wave-driven circulation is computed according to Ardhuin et al. (2008b) and Bennis et al. (2011). Wave forcing is based on the vortex force method which has been mainly validated for surf zone and also at coastal scales (e.g. Michaud et al. 2012; Moghimi et al. 2013; Bennis et al. 2014; Delpey et al. 2014; Bennis et al. 2016). This method considers the mean flow, represented by the quasi-Eulerian velocity (ie. the Lagrangian velocity minus the Stokes drift), rather than the total momentum, which removes the tricky problem of modelling the vertical flux of momentum (Ardhuin et al. 2008a). The generic formulation of momentum equations for a wave-forced, three-dimensional, incompressible, unsteady, hydrostatic, constant-density flow is :

$$
\frac{\mathrm{D} \widehat{\mathcal{U}}}{\mathrm{Dt}}=\mathbf{S}_{\mathbf{E P G}}+\mathbf{S}_{\mathbf{V M}}+\mathbf{S}_{\mathbf{H M}}+\mathbf{S}_{\mathbf{W P}}+\mathbf{S}_{\mathbf{B A}}+\mathbf{S}_{\mathrm{BBL}}+\mathbf{S}_{\mathbf{V F}}
$$

where $\widehat{\mathcal{U}}=(\widehat{U}, \widehat{V}, \widehat{W})$ is the $3 \mathrm{D}$ quasi-Eulerian velocity. The source terms $\mathbf{S}_{\mathbf{E P G}}, \mathbf{S}_{\mathbf{V M}}$, 
$\mathbf{S}_{\mathbf{H M}}, \mathbf{S}_{\mathbf{B A}}, \mathbf{S}_{\mathbf{B B L}}, \mathbf{S}_{\mathbf{V F}}, \mathbf{S}_{\mathbf{W P}}$ are related to the external pressure gradient, the vertical mixing, the horizontal mixing, the breaking acceleration, the streaming, the vortex force and the wave-induced pressure gradient, respectively. Wave-induced forcing terms are mainly the vortex force, the Bernouilli Head, the forces induced by the wave-to-ocean momentum flux, the wave-induced mixing and the wave-bottom interactions when the wave bottom boundary layer is solved. These terms influence source terms of (1) (more details in Bennis et al. 2011). This set of equations is compatible with that of McWilliams et al. (2004) used in Uchiyama et al. (2010) and Kumar et al. (2012).

Horizontal mixing is grid-spacing dependent as in Smagorinsky (1963) with horizontal viscosity $\left(\nu_{H}\right)$ defined as $\nu_{H}=f_{v i s c} \cdot 0.01 \cdot\left(\Delta_{x y}\right)^{1.15}$, where $\Delta_{x y}$ is the horizontal grid spacing and $f_{\text {visc }}$ is a user defined parameter (Okubo 1971).

The well-known k- $\epsilon$ turbulent scheme, modified according to Walstra et al. (2000) to include ocean wave effects, is used for the vertical mixing :

$$
\begin{aligned}
\frac{\partial k}{\partial t} & =\frac{1}{D^{2}} \cdot \frac{\partial}{\partial \varsigma}\left(\frac{\nu_{V}}{s_{k}} \cdot \frac{\partial k}{\partial \varsigma}\right)-\frac{\partial k}{\partial \varsigma} \cdot \frac{\partial \varsigma}{\partial t}+\operatorname{Prod}+\text { Buoy }-\epsilon+\mathcal{P}_{k} \\
\frac{\partial \epsilon}{\partial t} & =\frac{1}{D^{2}} \cdot \frac{\partial}{\partial \varsigma}\left(\frac{\nu_{V}}{s_{\epsilon}} \cdot \frac{\partial \epsilon}{\partial \varsigma}\right)-\frac{\partial \epsilon}{\partial \varsigma} \cdot \frac{\partial \varsigma}{\partial t}+\frac{\epsilon}{k}\left(c_{1} \operatorname{Prod}+c_{3} \text { Buoy }\right)+\mathcal{P}_{\epsilon}
\end{aligned}
$$

where $k$ is the turbulent kinetic energy and $\epsilon$ is the turbulent dissipation. $\nu_{V}$ is the vertical viscosity and depends on both mixing length and turbulent kinetic energy. Coefficients $c_{1}$, $c_{3}, s_{k}$ and $s_{\epsilon}$ are set according to Warner et al. (2005). Prod and Buoy terms represent the turbulent production by shear and buoyancy, respectively. Equations (2) and (3) differ from the classic ones : two source terms $\left(\mathcal{P}_{k}\right.$ and $\left.\mathcal{P}_{\epsilon}\right)$ were added to include the mixing effects relating to the bottom friction and wave breaking. At the surface, we preferred to use the Dirichlet boundary conditions of Kantha and Clayson (2004), because they are based on friction velocity, rather than the conditions of Walstra et al. (2000). Turbulent source terms depend on wave energy dissipated by bottom friction and wave breaking, near-bottom wave orbital velocity and wave bottom boundary layer thickness. They are linearly distributed over a characteristic depth, that is equal to the root mean square significant wave height divided by two near the surface and to the bottom boundary layer thickness near the bed (more details in Walstra et al. 2000). While other distributions, e.g. trigonometric functions, have been tested, only marginal differences have been noted.

Bottom friction and its enhancement by surface waves is parameterised with the formulation of Soulsby (1995), such that the bottom stress $\left(\tau_{b}\right)$ is :

$$
\tau_{b}=\left|\mathcal{T}_{\mathbf{c}}\right| \cdot\left[1+1.2\left(\frac{\left|\mathcal{T}_{w}\right|}{\left|\mathcal{T}_{w}\right|+\left|\mathcal{T}_{\mathbf{c}}\right|}\right)^{3.2}\right]
$$


where $\left|\mathcal{T}_{w}\right|$ and $\left|\mathcal{T}_{\mathbf{c}}\right|$ are the shear stresses related to waves and current dynamic, such that :

$$
\left|\mathcal{T}_{\mathbf{c}}\right|=\rho\left[\frac{\kappa}{\ln \left(\frac{z_{m}}{z_{0}}\right)}\right]^{2} \cdot\left|\mathbf{u}_{\mathbf{b}}\right|^{2},
$$

and

$$
\left|\mathcal{T}_{\mathbf{w}}\right|=\frac{1}{2} \rho f_{w}\left|\mathbf{u}_{\mathbf{o r b}}\right|^{2}
$$

where $z_{0}$ is the bottom roughness, $\rho$ is water mass density, $\mathbf{u}_{\mathbf{b}}$ and $\mathbf{u}_{\mathbf{o r b}}$ are the nearbed ocean velocity and wave orbital velocity, respectively, and $\kappa$ is Von-Karman's constant (set to 0.4$), f_{w}$ is the friction factor defined according to Soulsby (1995) and $z_{m}$ is a reference depth above the sea bed (where the flow velocity is assumed to follow a logarithmic law). Simulations using two different definitions of $z_{m}$ were carried out and their results were compared to provide a sensitivity analysis :

(H1). $z_{m}$ is the depth of the grid cell point nearest the bottom,

(H2). $z_{m}$ is a fraction of the mean depth.

Wave forcing terms of equations (1), (2), (3) and (4) are calculated using the mean wave parameters resulting from WW3. It solves the spectral wave action equation in space and time, from which spectrum based wave paramaters, atmosphere-waves and ocean-waves parameters and many more parameters are derived. The main purpose of this model is to simulate the wave generation by wind, dissipation and redistribution effects, their propagation by solving :

$$
\frac{D \mathbf{N}}{D t}=\frac{1}{\sigma}\left(\mathbf{S}_{\mathbf{l n}}+\mathbf{S}_{\mathrm{in}}+\mathbf{S}_{\mathrm{nl}}+\mathbf{S}_{\mathrm{ds}}+\mathbf{S}_{\mathrm{bot}}+\mathbf{S}_{\mathrm{db}}+\mathbf{S}_{\mathrm{tr}}+\mathbf{S}_{\mathrm{sc}}+\mathbf{S}_{\mathrm{ice}}+\mathbf{S}_{\mathrm{ref}}+\mathbf{S}_{\mathbf{m u d}}\right)
$$

where $\mathbf{N}(k, \theta ; \mathbf{x}, t)$ is the wave action density spectrum which is a function of time $(t)$, physical space $(\mathbf{x})$, wave number $(k)$ and wave direction $(\theta) . \sigma$ is the intrinsic wave radian frequency. Source terms are $\mathbf{S}_{\mathbf{l n}}, \mathbf{S}_{\mathbf{i n}}, \mathbf{S}_{\mathbf{n l}}, \mathbf{S}_{\mathbf{d s}}, \mathbf{S}_{\mathbf{b o t}}, \mathbf{S}_{\mathbf{d b}}, \mathbf{S}_{\mathbf{t r}}, \mathbf{S}_{\mathbf{s c}}, \mathbf{S}_{\mathbf{i c e}}, \mathbf{S}_{\text {ref }}, \mathbf{S}_{\text {mud }}$, respectively, for the linear wind input, exponential wind input, non-linear wind input, whitecapping dissipation, dissipation by bottom friction over sandy and rocky beds, depth-induced wave breaking dissipation, triad wave-wave interactions, bottom scattering, wave-ice interactions, reflection by shoreline or by floating icebergs and dissipation by viscous mud (more details can be found in Tolman and al. 2014).

For $\mathbf{S}_{\mathbf{i n}}+\mathbf{S}_{\mathbf{d s}}$, formulations of Ardhuin et al. (2010) and Filipot and Ardhuin (2012) (hereinafter ST4), and Zieger et al. (2015) (hereinafter ST6) have been tested. They aim to 
modelise the wind input, the swell dissipation and the wave breaking. Please note that ST4 and ST6 do not use a parametric tail in $f^{-5}$ at high frequencies. For $\mathbf{S}_{\mathbf{b o t}}$, two parameterisations (hereinafter BT1 and BT4) from the JONSWAP (Hasselmann et al. 1973) and SHOWEX (Ardhuin et al. 2003) experiments were evaluated. However, the results obtained with Hasselmann et al. (1973) were not shown here. For $\mathbf{S}_{\mathbf{d b}}$, the expression of Battjes and Janssen (1978) was chosen with the Miche-style shallow water limiter for maximum energy. For $\mathbf{S}_{\mathbf{n l}}$, the Discrete Interaction Approximation method (Hasselmann et al. 1985) was turned on. For $\mathbf{S}_{\text {ref }}$, the parameterisation of Ardhuin and Roland (2012) was activated.

\section{c. Coupling Procedure and Numerical Set-up}

The two-way coupling procedure was initially built by Bennis et al. (2011, 2013). Now, exchanges between the two models are managed by the automatic coupler OASIS (Valcke et al. 2015), instead of PALM (Buis et al. 2008). We defined a coupling time step that was greater than the models time steps. For each coupling time step, OASIS exchanges hydrodynamic variables among the two models, which will serve to calculate the forcing terms, as explained below. MARS computes hydrodynamic fields and sends, through the OASIS coupler, the surface flow velocities, as recommended by Banihashemi et al. (2017), and sea surface elevation to WW3. After several integration times, corresponding to one coupling time step, WW3 sends mean wave parameters, e.g. significant wave height and Bernouilli head, to MARS. The terms used in Eq. (1), (2), (3), (4), (6) are then calculated by MARS from these mean wave parameters and the MARS hydrodynamic is re-computed. Subsequently, the surface sea elevation and surface currents are re-sent to WW3 (see Figure 2), and so on.

We define two different coupling modes : i) the one-way mode (hereinafter OW) when WW3 forces MARS and ii) the two-way mode (hereinafter TW) where the feedback from MARS to WW3 is included in addition to the forcing of MARS by WW3.

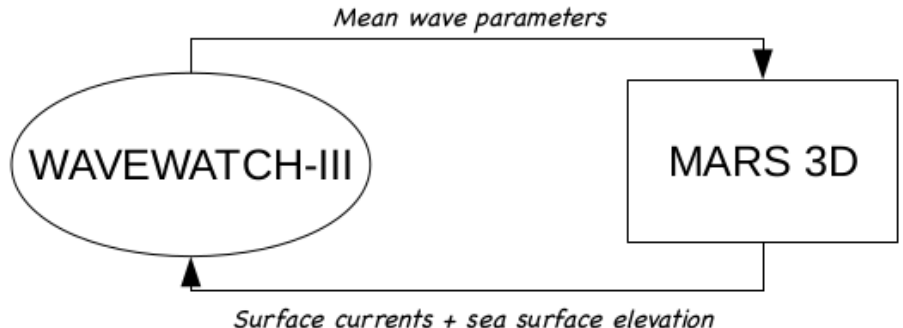

FiguRE 2: Coupling procedure. More details in Bennis et al. (2011).

Both models use two nested-grids (hereinafter parent and child grids), with similar horizontal resolutions $(600 \mathrm{~m}$ and $120 \mathrm{~m})$, that are shown on Figure 1a. Their South- 
West and North-East boundaries are : i) for parent grid : $47^{\circ} 53^{\prime} 60.0^{\prime \prime} \mathrm{N} / 6^{\circ} 03^{\prime} 32.4^{\prime \prime} \mathrm{W}$ $50^{\circ} 27^{\prime} 0.0^{\prime \prime} \mathrm{N} / 0^{\circ} 43^{\prime} 12.0^{\prime \prime} \mathrm{W}$, and ii) for child grid : $49^{\circ} 04^{\prime} 48.0^{\prime \prime} \mathrm{N} / 2^{\circ} 56^{\prime} 56.4^{\prime \prime} \mathrm{W}-50^{\circ} 4^{\prime} 12.0^{\prime \prime} \mathrm{N} /$ $1^{\circ} 23^{\prime} 24.0^{\prime \prime} \mathrm{W}$. All MARS simulations are in three dimensions with 12 sigma levels over the vertical. The wave model employs 32 frequencies from $0.04 \mathrm{~Hz}$ to $0.7678 \mathrm{~Hz}$ and 24 directions leading to a directional step of 15 degrees. Open boundaries of MARS are forced with the Shom CST France atlas that uses 114 tidal components (Leroy and Simon 2003). WW3 utilises wave spectra of the HOMERE and Ifremer databases (Boudiere et al. 2013) at its open boundaries. WW3 is forced by NCEP winds from CFSRR re-analysis. The deployment of child grids requires 2D-wave spectra, water levels and flow velocity from their parent grids at boundaries. All runs are coupled, with a one-way/two-way coupling for parent and child grids. The child grid coupling time step is $180 \mathrm{~s}$ and $20 \mathrm{~s}$ for one-way and two-way runs, respectively.

\section{d. Numerical Experiments}

A sensitivity analysis on the influence of main formulations and parameters is necessary to ensure a proper validation. The behaviour of the coupled model is assessed through different parameterisations for wave energy dissipation (ST4, ST6) and bottom friction (BT1, BT4). Moreover, the impact of bottom roughness $\left(z_{0}\right)$ and of the size of the near-bottom logarithmic layer $\left(z_{m}\right)$ are evaluated. Bottom stress in MARS is parameterised according to Eqs. (4), (5), (6) with (H1) and (H2) hypothesis for $z_{m}$. Tests are also carried out for the two coupling modes (OW and TW) in order to ensure cross validation. All sensitivity tests are not shown to avoid cluttering. So, only the relevant experiments were presented and they are summarised in Table 1. Runs 3, 4 and 7 included wave effects but not local wind effects while Runs 5 and 6 took into account the wave and local wind effects. The wave and wind effects were absent from Run 10 where the hydrodynamic was only drived by tides.

Model accuracy is evaluated through the root mean square error (RMSE), normalized root mean square error (NRMSE), BIAS, PBIAS, MAE and R-squared $\left(R^{2}\right)$, which are defined as follows (e.g. Allen et al. 2007b,a) :

$$
\begin{gathered}
\text { RMSE }=\frac{1}{N} \sqrt{\Sigma\left(X_{\text {model }}-X_{\text {data }}\right)^{2}}, \\
\text { NRMSE }=\frac{\text { RMSE }}{\max \left(X_{\text {data }}\right)-\min \left(X_{\text {data }}\right)}, \\
\text { BIAS }=\frac{\sum\left(X_{\text {model }}-X_{\text {data }}\right)}{N}, \quad \text { PBIAS }=100 \times \text { BIAS, }
\end{gathered}
$$




$$
\text { MAE }=\frac{\Sigma\left(\left|X_{\text {model }}-X_{\text {data }}\right|\right)}{N},
$$

301

$$
\mathrm{R}^{2}=1-\frac{\Sigma\left(X_{\text {data }}-X_{\text {model }}\right)^{2}}{\Sigma\left(X_{\text {data }}\right)^{2}}
$$

where $N$ is the total number of available samples, $X_{\text {model }}$ and $X_{\text {data }}$ are related to samples coming from numerical simulations and in-situ data, respectively. PBIAS gives a measure of whether the model is systematically underestimating or overestimating the measurements. The closer the value is to zero the better the model. Performance levels regarding |PBIAS| are categorised as follows $\leq 10$ excellent, $10-20$ very good, $20-40$ good, $\geq 40$ poor (Marechal 2004; Allen et al. 2007a). $R^{2}$ is a statistical measure of how close the data to the fitted regression line. $R^{2}=1$ indicates that model results and data are similar. Performance levels regarding $R^{2}$ are categorised as : $\geq 0.65$ excellent, $0.65-0.5$ very good, $0.5-0.2$ good, $\leq 0.2$ poor (Marechal 2004). The choice of category boundary is subjective, these criteria are not of the fail/pass type, but valuate the performance in four categories from excellent to poor.

\begin{tabular}{|l|l|l|l|l|l|}
\hline & Year & $\begin{array}{l}\text { Wave } \\
\text { energy } \\
\text { dissipa- } \\
\text { tion }\end{array}$ & $\begin{array}{l}\text { Wave } \\
\text { bottom } \\
\text { friction }\end{array}$ & $\begin{array}{l}\text { Coupling } \\
\text { mode }\end{array}$ & $\begin{array}{l}\text { Local } \\
\text { wind ef- } \\
\text { fects }\end{array}$ \\
\hline Run 3 & 2017 & ST6 & BT4 & TW & NO \\
\hline Run 4 & 2017 & ST6 & BT4 & OW & NO \\
\hline Run 5 & 2017 & ST4 & BT4 & OW & YES \\
\hline Run 6 & 2017 & ST4 & BT4 & TW & YES \\
\hline Run 7 & 2017 & ST4 & BT4 & TW & NO \\
\hline Run 10 & 2017 & - & - & - & NO \\
\hline
\end{tabular}

TABLE 1: List of numerical experiments according to date, wave energy dissipation formulation, wave bottom friction parameterisation, coupling mode and the inclusion of local wind effects. All runs include wave effects except for Run 10 in italics.

\section{Results and Discussion}

Model tests against ADCP, wave buoys and tidal gauge data are presented. Numerical validations are related to tidal elevation, mean wave parameters, wave spectra, time series and 
vertical profiles of the tidal stream velocity. We investigated how ocean waves interact with the tidal current in Alderney Race for different met-oceanic conditions. Effects of bottom friction, bottom roughness, direction of propagation of wave and current, and turbulence modelling are discussed.

\section{a. Tidal Elevation}

Tidal range varies between 4 and $7 \mathrm{~m}$ for the studied area and time period. Comparisons between measurements of tidal gauges (TG1 and TG2) and numerical simulations of MARSWW3 are shown on Figure 3. Our coupled model produces mean sea surface elevation values with a terrestrial definition (IGN 69) for the vertical reference. As TG1 and TG2 measurements use the levels of the lowest tide, chart data as vertical references, we shifted the simulated water level with $3.88 \mathrm{~m}$ for TG1 and $5.55 \mathrm{~m}$ for TG2 as recommended by Shom (2017) to provide a commensurable comparison. This correction, based on the mimimum BIAS, is consistent with the measured mean sea level of $3.87 \mathrm{~m}$ and $5.45 \mathrm{~m}$ in Cherbourg and Dièlette in 2017, respectively (Shom 2017).

Model and data results were close at Cherbourg (TG1), with good fits in amplitude and time phasing (see Figure 3, black dots and red line). Absolute error (hereinafter AE) were around few tens of centimetres, with a maximum values of $0.39 \mathrm{~m}$ (see Table 2). RMSE was $0.13 \mathrm{~m}$ and $\mathrm{R}^{2}=0.98$, that is excellent. Errors mainly occured just before the high tide, showing that the tidal asymmetry was not well represented in some cases. At Dielette (TG2), numerical simulations were worse than in Cherbourg but they were acceptable, with BIAS $=0.02 \mathrm{~m}, \mathrm{RMSE}=0.44 \mathrm{~m}$ and $\mathrm{R}^{2}=0.95$. However, discrepancies were observed with a phase delay up to few minutes for some tidal cycles. In contrast, this problem was absent in Cherbourg (TG1). This illustrates the complexity of the tidal dynamic around La Hague Cape where the tidal range increases by 5 metres within a few kilometres, as shown in Bailly Du Bois et al. (2012). This could be ascribed to bathymetry errors and bottom stress that is strongly impacted by such errors (more details in Section 3c). 


\begin{tabular}{|c|c|c|}
\hline & & 21-25 Nov 2017 \\
\hline TG1 (Cherbourg) & $\max (\mathrm{AE})$ & $0.39 \mathrm{~m}$ \\
\hline & $\min (\mathrm{AE})$ & $-0.16 \mathrm{~m}$ \\
\cline { 2 - 3 } & $\mathrm{BIAS}$ & $0.06 \mathrm{~m}$ \\
\cline { 2 - 3 } & $\mathrm{RMSE}$ & $0.13 \mathrm{~m}$ \\
\hline \multirow{3}{*}{ TG2 (Dièlette) } & $\max (\mathrm{AE})$ & $0.73 \mathrm{~m}$ \\
\cline { 2 - 3 } & $\min (\mathrm{AE})$ & $-0.34 \mathrm{~m}$ \\
\cline { 2 - 3 } & $\mathrm{BIAS}$ & $0.02 \mathrm{~m}$ \\
\cline { 2 - 3 } & $\mathrm{RMSE}$ & $0.44 \mathrm{~m}$ \\
\hline
\end{tabular}

TABLE 2: Maximum $(\max (\mathrm{AE}))$ and minimum $(\min (\mathrm{AE}))$ values of $\mathrm{AE}$ are presented as well as BIAS and RMSE for TG1 and TG2. Positive and negative signs denote under-estimation and over-estimation of water levels by the model, respectively.

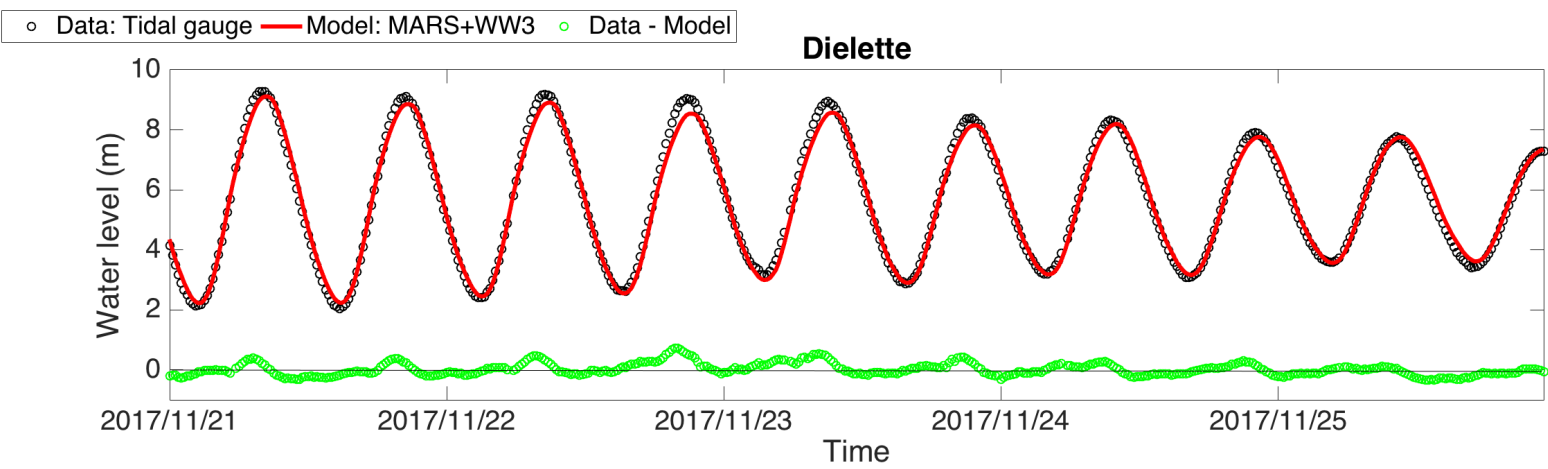

347

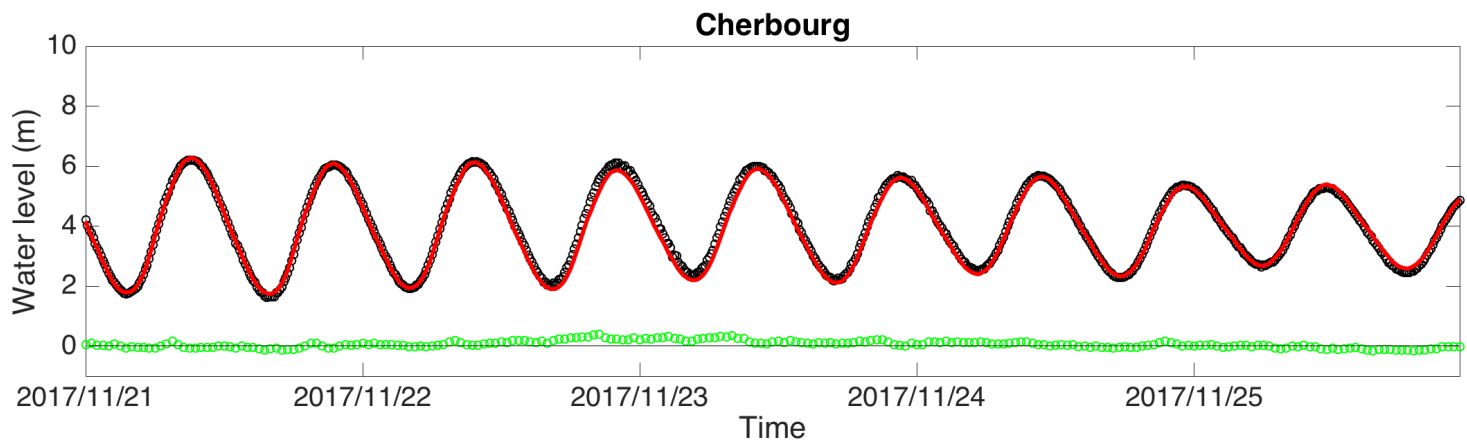

Figure 3: Water level at Dielette (TG2, top row) and Cherbourg (TG1, bottom row) measured by Shom tidal gauge (black dots) and computed by the coupled model (red solid line) over 5 days from 21 to 25 November 2017. AE is represented in green dots at each time.

b. Sea States

Sea states in Alderney Race are often complex, with wind seas combined with swells from the Atlantic Ocean (Maisondieu 2016). Comparisons between numerical simulations and 
measurements were performed in order to investigate how wave-current interactions influence ocean waves in Alderney Race. Several parameterisations for the wave energy dissipation by whitecapping and bottom friction were evaluated. Moreover, water level and surface current effects on the wave field are presented and discussed as well as local wind effects.

Time series of the magnitude (hereinafter $\mathrm{U}_{10}$ ) and direction (hereinafter $\mathrm{Udir}_{10}$ ) of the wind at 10 metres above ground level (see Figure 4) showed high values for $\mathrm{U}_{10}$ during the night of 22-23 November, with a maximum value around $17.5 \mathrm{~m} / \mathrm{s}$, and for a NorthNorth-East to South-South-West wind. The wind simulated by CFSRR, that have a spatial resolution of $0.2^{\circ}$ of latitude and of $0.1^{\circ}$ of longitude at the study site location, is used to force WW3. Wind forcing was in agreement with the wind measured at Goury by the semaphore (see Figure 4). NRMSE is around 0.11 (see Table 3) while PBIAS is positive for $\mathrm{U}_{10}$, indicating that the CFSRR values were higher than the measured ones. However, PBIAS remains very good for $\mathrm{U}_{10}$ (around 14\%) while MAE is excellent for $\mathrm{Udir}_{10}$ (around 7\%). The discrependancies can be explained by the coarse resolution of the CFSRR model, the distance (around $7 \mathrm{~km}$ ) between Goury and the ADCP point (Coelingh et al. 1996, 1998), and also because the semaphore data are recorded above ground level that influences the atmospheric boundary layer and the wind velocity (e.g. Bailly Du Bois and Dumas 2005). The significant wave height recorded by ADCP was highest on 23 November at $2: 13$ a.m. and $3: 13$ a.m., reaching $4 \mathrm{~m}$ and $3.6 \mathrm{~m}$, respectively. During this time period, high winds were measured with $\mathrm{U}_{10}$ values greater than $15 \mathrm{~m} / \mathrm{s}$. As a result the inclusion of local wind effects has improved the simulated significant wave height (see Figures 5 and 6 a, Run 3 vs Run 6, and Table 4), in particular between the 22 November at 12 a.m. and the 23 November at 12 p.m, where $\mathrm{U}_{10}$ was highest. NRSME has been reduced by $50 \%$ and now reached 0.08 for Run 6. PBIAS were high for Run 3 (around 25\%) and Run 4 (around 28\%) and showed that the significant wave height was largely underestimated by the model. With local wind effects, PBIAS decreased substantially to $5.8 \%$ for Run 6 (see Table 4), that is excellent. R-squared values and scatter plots of Figure 5 well illustrated how the local wind effects have improved the fit to data, with $R^{2}=0.97$ for Run 6 instead of 0.87 for Run 3 .

The wave-to-ocean momentum flux is enhanced due to local wind effects, particularly for the zonal component, which was 60-fold increase, when wind blows hard (on 23 November around 2 a.m). This increase is ascribed to changes in both wind speed (from $12 \mathrm{~m} / \mathrm{s}$ on 22 November around 12 p.m. to $17.5 \mathrm{~m} / \mathrm{s}$ on 23 November around 2 a.m) and direction (from South-South-West direction on 22 November around 12 p.m. to West direction on 23 November around 2 a.m) during the storm. Wave direction was worse for simulations with local wind effects between the 22 November at 12 a.m. and the 23 November at 12 p.m. compared to the simulations without such effects (see Figure 6b, Run 3 vs Run 6). With local wind effects, waves tend to go towards the North everytime instead of turning East 
(more explanations hereafter). From the 23 November at 12 p.m to 25 November 11 p.m., wave direction fitted well to the observations. Therefore, only this time period will study in the next section (3c), which deals with waves effects on tidal currents, because changes in currents due to the waves are partly drived by the direction of propagation of waves, that should be well represented to perform a right analysis.

One of most important physical phenomenon in Alderney Race is the wave refraction ascribed to the strong tidal current. This phenomenon was well simulated by the coupled model, particularly when the local wind effects were not included in simulations (see Figure 6b, Runs 3 and 6) : refraction has modified wave direction, which was in the agreement with observations and former studies (e.g. Wolf and Prandle 1999; Ardhuin et al. 2012). When wind blowed hard, local wind effects (see Figure 6b, Run 6) tended to smooth refraction effects because currents were abnormally reduced (more details in section 3c) and therefore they had less influence on surface waves. Runs 4 and 5, which did not include neither current effects on waves nor local wind effects, failed to correctly reproduce the measured wave direction. A modulation of significant wave height was also observed due to refraction (Figure 6 a ; Runs 3 vs 4 or Run 5 vs 6). Both parameterisations for wave breaking dissipation (ST4 and ST6) adequately simulated modifications in the significant wave height and wave-toocean momentum flux by tide (see Figures $6 a$,c,d; Runs 3 vs 4 or Run 5 vs 6 ). The eastward and northward components of the momentum flux displayed peak values during the ebb, when the tidal current was southwestward (see Figures 6c,d; Runs 3 vs 6). In that case, interactions between ocean waves and tide generated wave breaking events that produced an enhanced wave-to-ocean momentum flux. This is highly visible if we compare the results of the two coupling modes (see Figure 6c,d ; Runs 3 vs 4 or Run 5 vs 6 ) : peaks were absent from Runs 4 and 5 because they did not take into account the current effects.

Tide also influences the near-bed orbital velocity, and particularly its meridional component (Figure 6f, Run 3 and 6) because of the tidal current direction, that was NNE/SSW. For the Runs 3 and 6, near-bed orbital velocity was modulated by tides with high and low values during ebb and flood, respectively. In contrast, Runs 4 and 5, being computed without interactions with the flow, did not have such peaks (see Figure 6f), showing the impact of wave-current interactions. The zonal component of the near-orbital velocity was the highest due to the direction of wave propagation, that was mainly from West to East. Its form resembles significant wave height, with maximum values during the night of 22-23 November (see Figure 6e). The effects of local wind on the near-bed wave orbital velocity are light in comparison with the tidal ones, except for the 23 November around 2 a.m. where an increase of $5 \mathrm{~cm} / \mathrm{s}$ was observed due to the strong wind. On the whole, parameterisations for wave bottom friction of Hasselmann et al. (1973) and Ardhuin et al. (2003) produced close near-bed results. 
The wave-current interactions are also visible on the frequency wave energy spectra (see Figure 8). To study it in details, we selected eight moments that differ in terms of type of wave-current interactions (various waves and current directions, low/high tide, flood/ebb tide, low/high flow velocity). All related informations are summarised in Table 5. All presented spectra were bi-modal with a swell component, where the maximum of energy was located in $f_{p, \text { swell }}=0.07812 \mathrm{H}_{\mathrm{z}}\left(\mathrm{RTF} 2, \mathrm{RTE} 1\right.$ and RTE2) and $f_{p \text {,swell }}=0.09375 \mathrm{H}_{\mathrm{z}}(\mathrm{RTF} 1)$, and a wind-wave component, which reached its maximum in $f_{p \text {,windsea }}=0.125 \mathrm{H}_{\mathrm{z}}(\mathrm{RTF} 2$, RTE1 and RTE2) and $f_{p \text {,windsea }}=0.1406 \mathrm{H}_{\mathrm{z}}$ (RTF1). The splitting frequency $\left(f_{c}\right)$ is around $0.11 H_{z}$. For the swell component, all runs produced similar results, that are in agreement with the ADCP measurements regardless of coupling mode, wave dissipation parameterisation and local wind effects (see Figure 8). For the wind component, a wave energy decay in $f^{-4}$ for frequencies between $f_{p \text {,windsea }}$ and $3 f_{p \text {,windsea }}$ is observed, as demonstrated by Toba (1973), Donelan et al. (1985) and others. When frequencies were greater than $3 f_{p \text {,windsea }}$, a decay in $f^{-5}$ is found, as defined in Phillips (1958). Numerical results were consistent with the ADCP data for all runs up to $2 f_{p \text {,windsea }}$. Runs 5 and 6 , which have integrated local wind effects in simulations, overestimated the wave energy beyond $2 f_{p, \text { windsea }}$ and had an energy tail in $f^{-4}$. Run 7 , which used the same parameterisation for the wave energy dissipation (ST4) than Runs 5 and 6, did not suffer to this overestimation, showing that the influence of local wind effects on ST4.
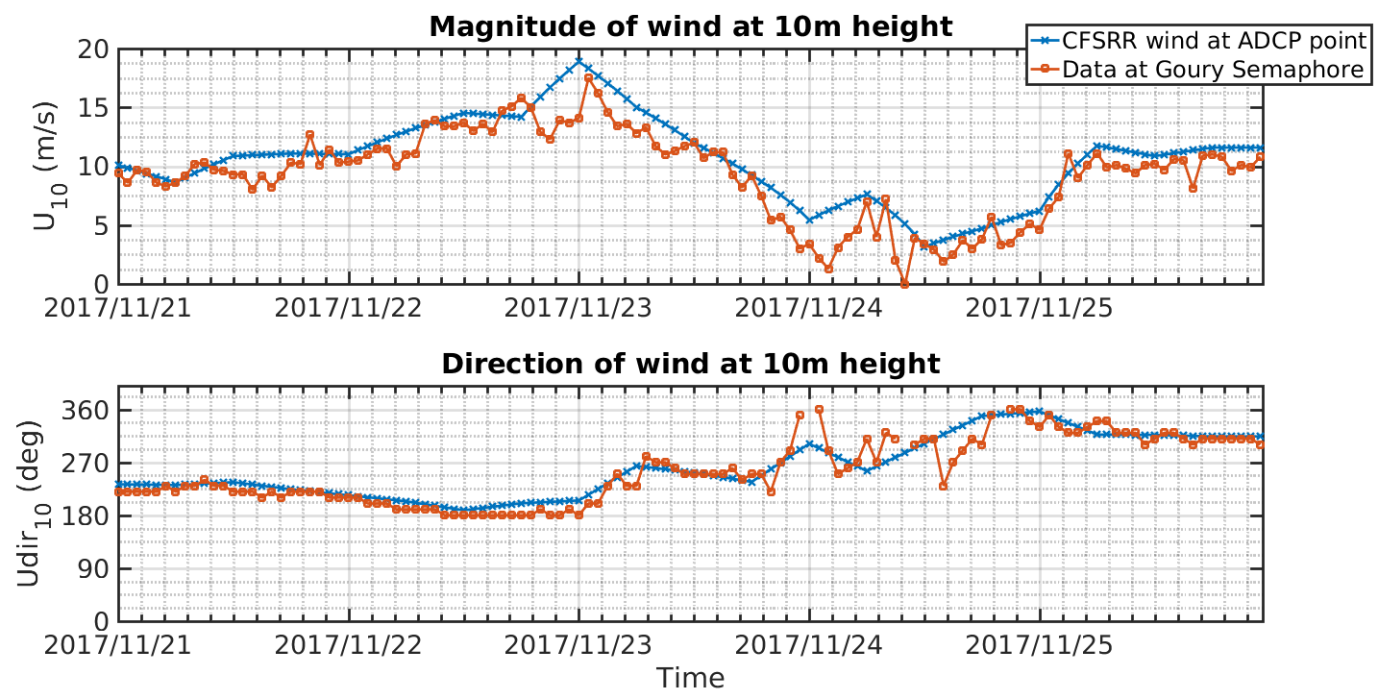

FiguRE 4: Time series for $\mathrm{U}_{10}$ (top panel) and $\mathrm{Udir}_{10}$ (bottom panel) : CFSRR inputs are in blue and data from the Goury semaphore are in red.

\begin{tabular}{|l|l|l|l|}
\hline & NRMSE & $\mathbf{R}^{\mathbf{2}}$ & PBIAS (\%) \\
\hline $\mathbf{U}_{\mathbf{1 0}}$ & 0.10 & 0.96 & 13.97 \\
\hline Udir $_{\mathbf{1 0}}$ & 0.11 & 0.98 & 3.82 \\
\hline
\end{tabular}

TABLE 3: NRMSE, $\mathrm{R}^{2}$ correlation and PBIAS for $\mathrm{U}_{10}$ and $\mathrm{Udir}_{10}$. 


\begin{tabular}{|l|l|l|l|l|}
\hline & Runs & NRMSE & $\mathbf{R}^{\mathbf{2}}$ & PBIAS (\%) \\
\hline $\mathbf{H}_{\mathbf{S}}$ & Run 3 & 0.16 & 0.87 & -27.95 \\
& Run 4 & 0.16 & 0.87 & -25.57 \\
& Run 5 & 0.10 & 0.95 & 12.07 \\
& Run 6 & 0.08 & 0.97 & 5.89 \\
\hline
\end{tabular}

TABLE 4: NRMSE, $\mathrm{R}^{2}$ correlation and PBIAS for significant wave height $\left(\mathrm{H}_{\mathrm{s}}\right)$. Runs 3,4 ,

\begin{tabular}{|l|l|l|l|l|l|}
\hline & Date & W $\perp$ C & W+C & $\mathrm{U}_{\mathrm{c}}^{\mathrm{s}}(\mathrm{m} / \mathrm{s})$ & $\mathrm{SSH}(\mathrm{m})$ \\
\hline $\begin{array}{l}\text { RTF1 } \\
\text { (flood) }\end{array}$ & $\begin{array}{l}23 / 11 / 2017 \\
10: 45 \text { p.m. }\end{array}$ & $\mathrm{X}$ & & 2.01 & 1.87 \\
\hline $\begin{array}{l}\text { RTF2 } \\
\text { (flood) }\end{array}$ & $\begin{array}{l}24 / 11 / 2017 \\
00: 45 \text { a.m. }\end{array}$ & $\mathrm{X}$ & & 1.13 & 0.67 \\
\hline $\begin{array}{l}\text { RTE1 } \\
\text { (ebb) }\end{array}$ & $\begin{array}{l}24 / 11 / 2017 \\
02: 45 \text { a.m. }\end{array}$ & & $\mathrm{X}$ & 0.93 & -1.18 \\
\hline $\begin{array}{l}\text { RTE2 } \\
\text { (ebb) }\end{array}$ & $\begin{array}{l}24 / 11 / 2017 \\
03: 45 \text { a.m. }\end{array}$ & & $\mathrm{X}$ & 1.99 & -1.82 \\
\hline $\begin{array}{l}\text { RTF3 } \\
\text { (flood) }\end{array}$ & $\begin{array}{l}25 / 11 / 2017 \\
11: 00 \text { a.m. }\end{array}$ & $\mathrm{X}$ & & & \\
\hline $\begin{array}{l}\text { RTF4 } \\
\text { (flood) }\end{array}$ & $\begin{array}{l}25 / 11 / 2017 \\
01: 45 \text { p.m. }\end{array}$ & & $\mathrm{X}$ & 0.63 & 0.11 \\
\hline $\begin{array}{l}\text { RTE3 } \\
\text { (ebb) }\end{array}$ & $\begin{array}{l}25 / 11 / 2017 \\
04: 15 \text { p.m. }\end{array}$ & & $\mathrm{X}$ & 1.56 & -1.47 \\
\hline $\begin{array}{l}\text { RTE4 } \\
\text { (ebb) }\end{array}$ & $\begin{array}{l}25 / 11 / 2017 \\
05: 00 \text { p.m. }\end{array}$ & & $\mathrm{X}$ & 2.07 & -1.73 \\
\hline
\end{tabular}

TABLE 5: Waves-current direction $(\mathrm{W} \perp \mathrm{C}$ when waves and current direction are orthogonal and $\mathrm{W}+\mathrm{C}$ for an angle between waves and current direction less than $80^{\circ}$ ), surface current velocity $\left(\mathrm{U}_{\mathrm{c}}^{\mathrm{s}}\right.$ ) and sea surface height $(\mathrm{SSH})$ at RTF1, RTF2, RTE1, RTE2, RTF3, RTF4, RTE3 and RTE4. Directions follow the oceanographical convention for the flow and the meteorological convention for waves. Values are from numerical simulations. 


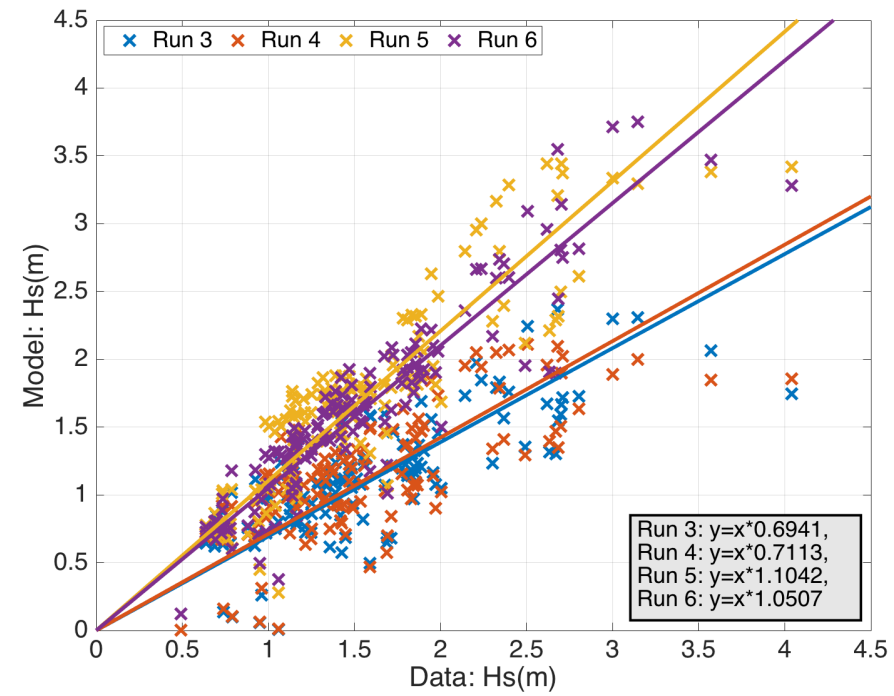

Figure 5: Scatter plots for the significant wave height $\left(\mathrm{H}_{\mathrm{s}}\right)$ for Run 3 (blue crosses), Run 4 (red crosses), Run 5 (yellow crosses) and Run 6 (purple crosses). In-situ data and model results are drawn along $\mathrm{x}$-axis and $\mathrm{y}$-axis, respectively. Regression lines are plotted in blue, red, yellow and purple solid lines for runs 3, 4, 5 and 6 , respectively. 

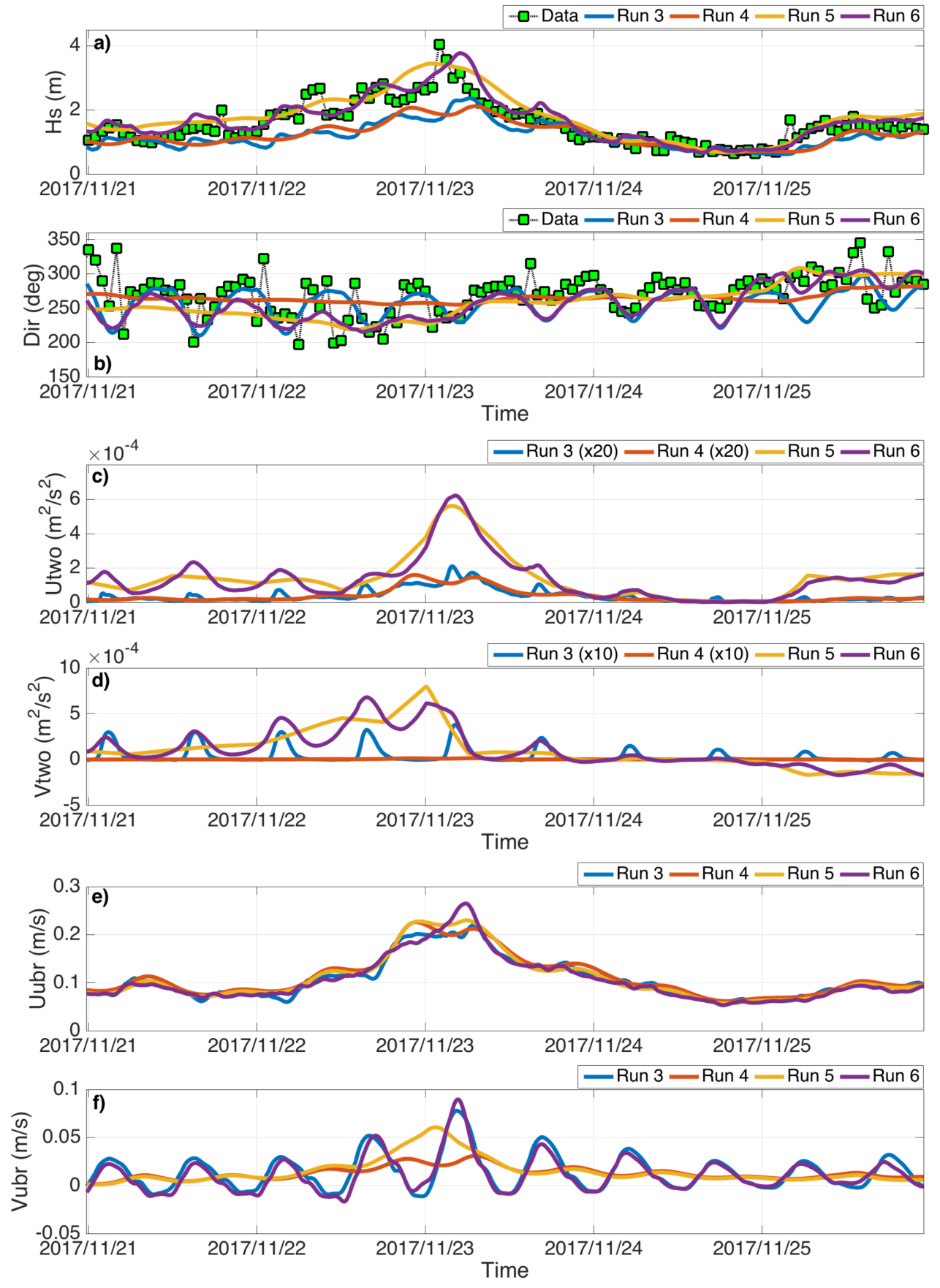

Figure 6: Time series of sea states characteristics, from 21 to 25 November 2017, integrated over frequencies (32) and directions (24) : a) significant wave height, b) wave direction (meteorological convention), c) zonal component of wave-to-ocean momentum flux, d) meridional component of wave-to-ocean momentum flux, e) zonal component of near-bed wave orbital velocity, f) meridional component of near-bed wave orbital velocity. ADCP data are in black-green squares while numerical results for Runs 3, 4, 5 and 6 are in blue, red, yellow and purple solid lines, respectively. 

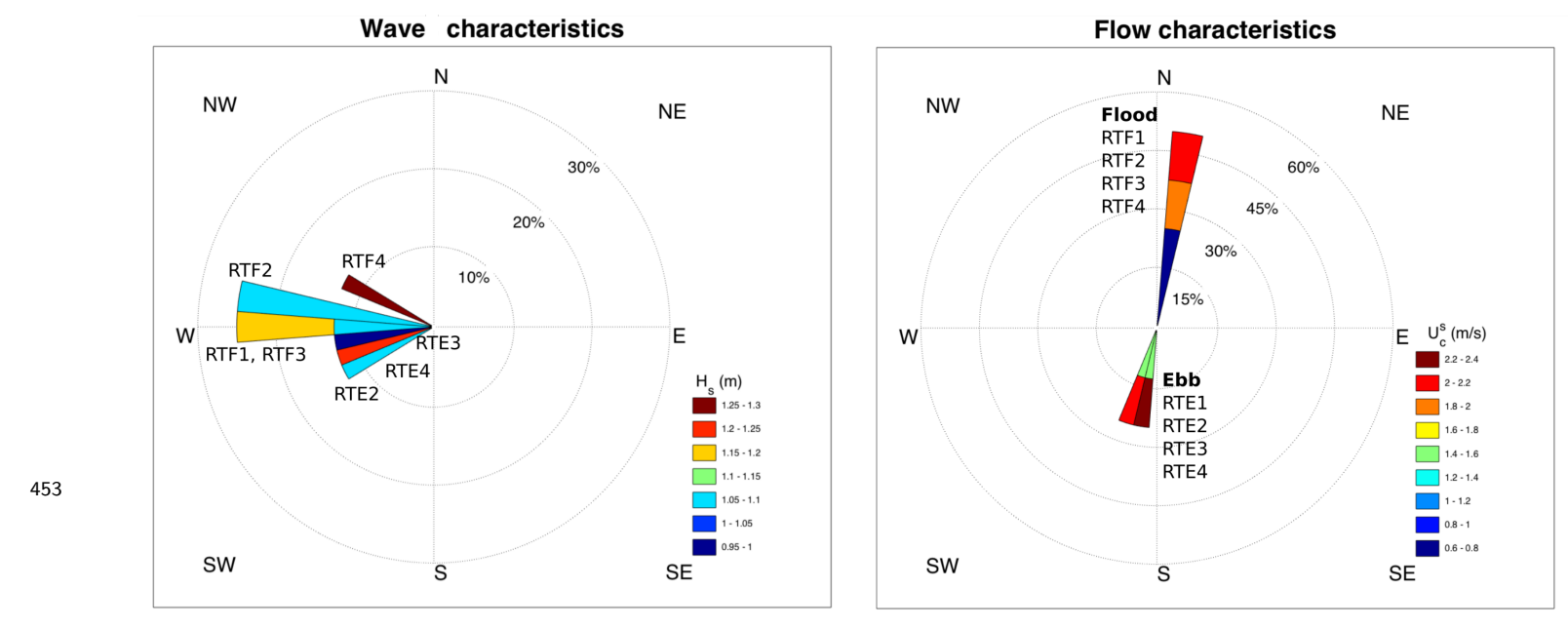

Figure 7: Left panel : Wave direction (polygon) and significant wave height (color). Right panel : Direction (polygon) and velocity magnitude (color) of the current. Only RTF1, RTF2, RTE1, RTE2, RTF3, RTF4, RTE3 and RTE4 are shown. Directions follow the oceanographical convention for the flow and the meteorological one for waves. Results are from numerical simulations.

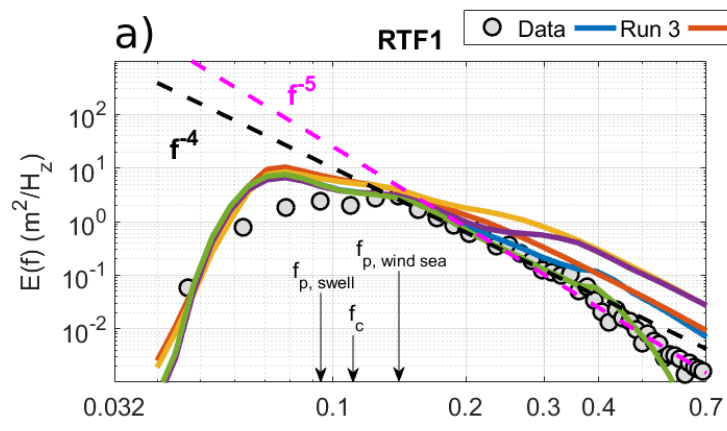

b)
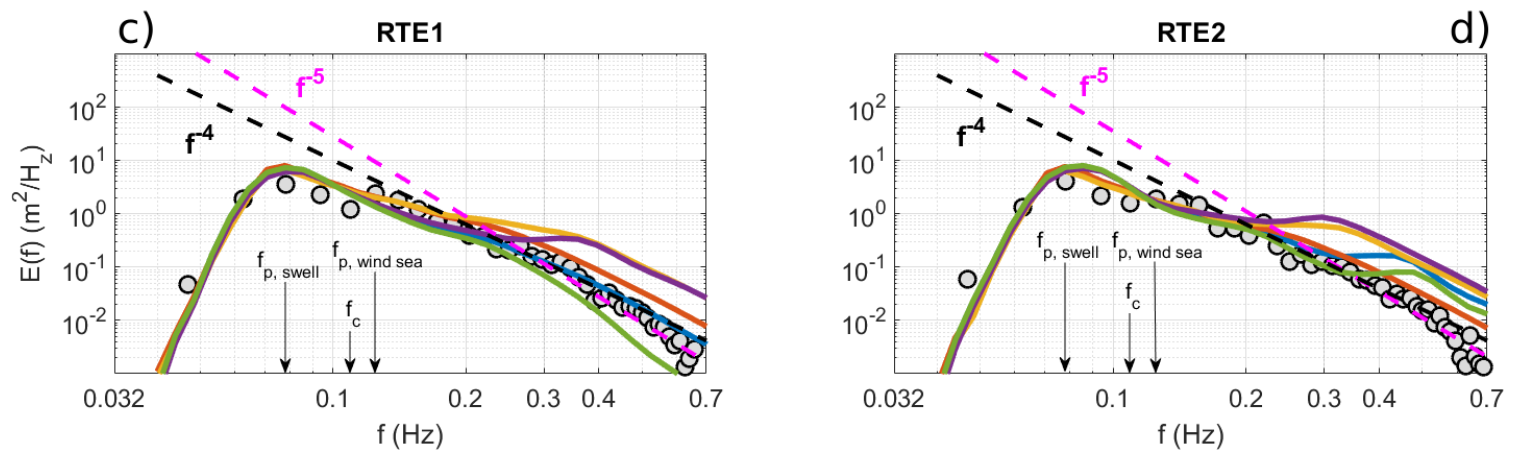

Figure 8: Frequency wave energy spectra at : a) RTF1, b) RTF2, c) RTE1 and d) RTE2. The first $(a, b)$ and second $(c, d)$ rows are for flood and ebb tides, respectively. Magenta and black dashed lines are for $o\left(f^{-5}\right)$ and $o\left(f^{-4}\right)$, respectively. Note that the $\mathrm{x}$-axis and $\mathrm{y}$-axis are a $\log 10$ scale. $\mathrm{f}_{\mathrm{p}, \mathrm{swell}}, \mathrm{f}_{\mathrm{p} \text {,windsea }}, \mathrm{f}_{\mathrm{c}}$ (around $0.11 \mathrm{H}_{\mathrm{z}}$ ) represent the peak frequency for swell and wind sea, and the splitting frequency, respectively. 
c. Time Series of the Tidal Stream Velocity

We now investigate how the Alderney Race circulation was impacted by ocean waves. Figure 9 shows time series of magnitude and direction of the measured current velocity at 25, 12 and 6 meters depth above seabed at the ADCP location between 23 November 2017 at 12 p.m and 25 November 2017 at 8 p.m, where the tidal flow velocity varied between 0 and 2.5 $\mathrm{m} / \mathrm{s}$. First, we start by discussing the results without local wind effects (Runs 3 and 10). On the whole, the numerical results for cases with (Run 3) and without waves (Run 10) were consistent with the data and were close each other (see Figures 9 and 10 and Table 6). Good and similar NRSME (0.09 and 0.11) and $R^{2}$ (0.97 and 0.98) for both runs were observed. PBIAS were excellent, because they range from $0.6 \%$ to $3.8 \%$, but they showed that velocity was underestimated by the model when wave effects were activated while an overestimate occurred where wave effects were disabled. Wave effects tend to reduce systematically the velocity magnitude (e.g. Grant and Madsen 1979; Xie et al. 2001; Zhang et al. 2004) due to wave enhancement of bottom friction. At low tide, as the model without waves overestimated tidal velocity, simulations with waves had a better fit with in-situ data. Flow direction (see Figure 9d), and its changes belonging to the tidal cycle were well reproduced by the model. Close results were obtained for Run 3 (TW mode) and Run 4 (OW mode, not displayed here). Even if current and sea level produced significant changes in the wave field (see Figure $6)$, the impact of feedback on the tidal current and water level remained weak.

As regards the cases taking into account local wind effects (Runs 5 and 6 ) and between the 23 November 12 p.m. and 25 November 2 a.m., tidal current were little impacted by local wind effects and numerical results were close to the data (see Figure 9). Indeed, NRMSE (around 0.11 ), $R^{2}$ (around 0.97 ) and PBIAS $(0.62 \%-3.79 \%)$ were in the same order of magnitude for Run 3 (without local wind) and Run 6 (with local wind). That could be explained by the wind speed at the ADCP point which was weak for this time period, ranging from 4 to $10 \mathrm{~m} / \mathrm{s}$ (see Figure 4). Beyond the 25 November at 2 a.m., when the wind started blowing, a strange behaviour was observed, particularly during the flood with a change in current direction, that induced a loss in the current intensity of around $0.5 \mathrm{~m} / \mathrm{s}$, with a smoother transition between ebb and flood directions and a shift in direction to the East. As the tidal current direction was modified, wave-current interactions were impacted. The decrease in velocity magnitude being similar for Runs 5 and 6 , that is not induced by a change in wave field due to wave-current interactions. During this time period, waves went towards the East (see Figure 6b), and therefore the change in tidal current direction has reduced the angle between waves and current, leading to a decrease in the current intensity, as reported by Groeneweg and Klopman (1998). As a result, this problem comes from the ocean model MARS and suggests a mis-evaluation of the wind effects on the flow and particularly of the wind stress. Further investigations are required. 
We noted an occasional phase delay that varied over time from 0 to 30 min. The delays differed depending to the tidal cycles. For example, in tidal cycles containing RTF1, RTF2, RTE1 and RTE2, the phase delay was constant at $15 \mathrm{~min}$ and in the same direction for all runs, regardless the coupling mode and the local wind effects. In contrast, we noted different time delays at RTF3 (no time delay for runs with and without local wind effects), RTF4 (30 min and no time delay for runs without and with local wind effects, respectively), RTE3 (30 min and no time delay for runs without and with local wind effects, respectively) and RTE4 (15 min for runs with and without local wind effects) times, which were part of the same tidal cycle. It is interesting to see that the delay was removed in simulations with local wind effects at RTF3, RTF4 and RTE3. That suggests that time delay could be due to waves and wind through the bottom stress, which was based on the near-bed wave orbital velocity. In addition, the maximum value of 30 min often corresponded to the reverse tide occurring sooner in the in-situ dataset. At this time, waves effects on the current were strongest. To investigate the role of waves and wind, measurements of the near-bed wave orbital velocity are required.

Furthermore, time delay could be partially corrected by expressing $z_{m}$ (Eq. (5)) as a fraction of the mean depth (D). In this study and after many simulations, the fraction was set to $5 \%$. Some sensitivity tests were performed with $z_{m}$ at $50 \%$ (Uchiyama et al. 2009), $26.7 \%, 11.4 \%, 5.71 \%, 2.67 \%$ and $1.33 \%$ of $\mathrm{D}$ and the related velocities are presented in Figure 11. A one-hour delay was observed, as shown on Figure 11, between both extreme cases $(50 \%$ and $1.33 \%$ of $\mathrm{D})$, highlighting the link between the bottom stress formulation and time delay. Tidal asymmetry also appeared also to be sensitive to the $z_{m}$ value, with differences between tidal phases that were accentuated by large $z_{m}$ values. Because the depth where the logarithmic profile is imposed was strongly dependent on the turbulence level, these tests showed that one of the sources of the time delay was ascribed to the modification of the turbulence level by the interactions between seabed morphology, ocean waves and tidal current. Parameterisation using an apparent roughness as recommended by Grant and Madsen (1979); Signell et al. (1990); Mathisen and Madsen (1999) may be a way of improvement, in addition to use of high spatial resolution bathymetry based on Furgerot et al. (2019). 


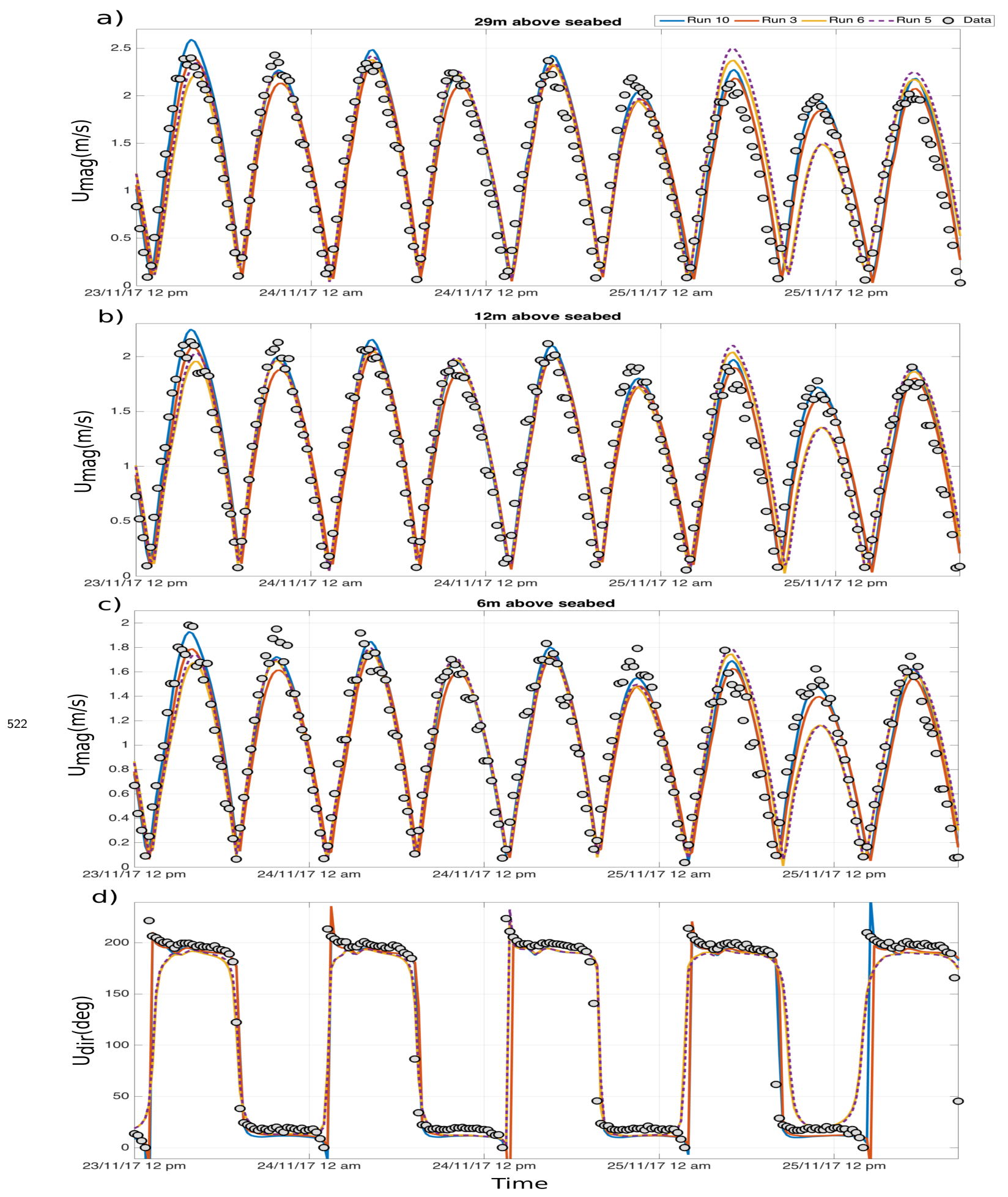

Figure 9: Time series of magnitude (a,b,c) and direction (d) of the current velocity at $29 \mathrm{~m}$ (a), $12 \mathrm{~m}(\mathrm{~b}, \mathrm{~d}), 6 \mathrm{~m}$ (c) depth above seabed. All panels show numerical results for Runs 3 (TW, red solid line), 5 (OW+local wind effects, purple dash line), 6 (TW+local wind effects, yellow solid line) and 10 (without waves, blue solid line). In-situ data are shown with black circles. Directions are based on oceanographic conventions. 

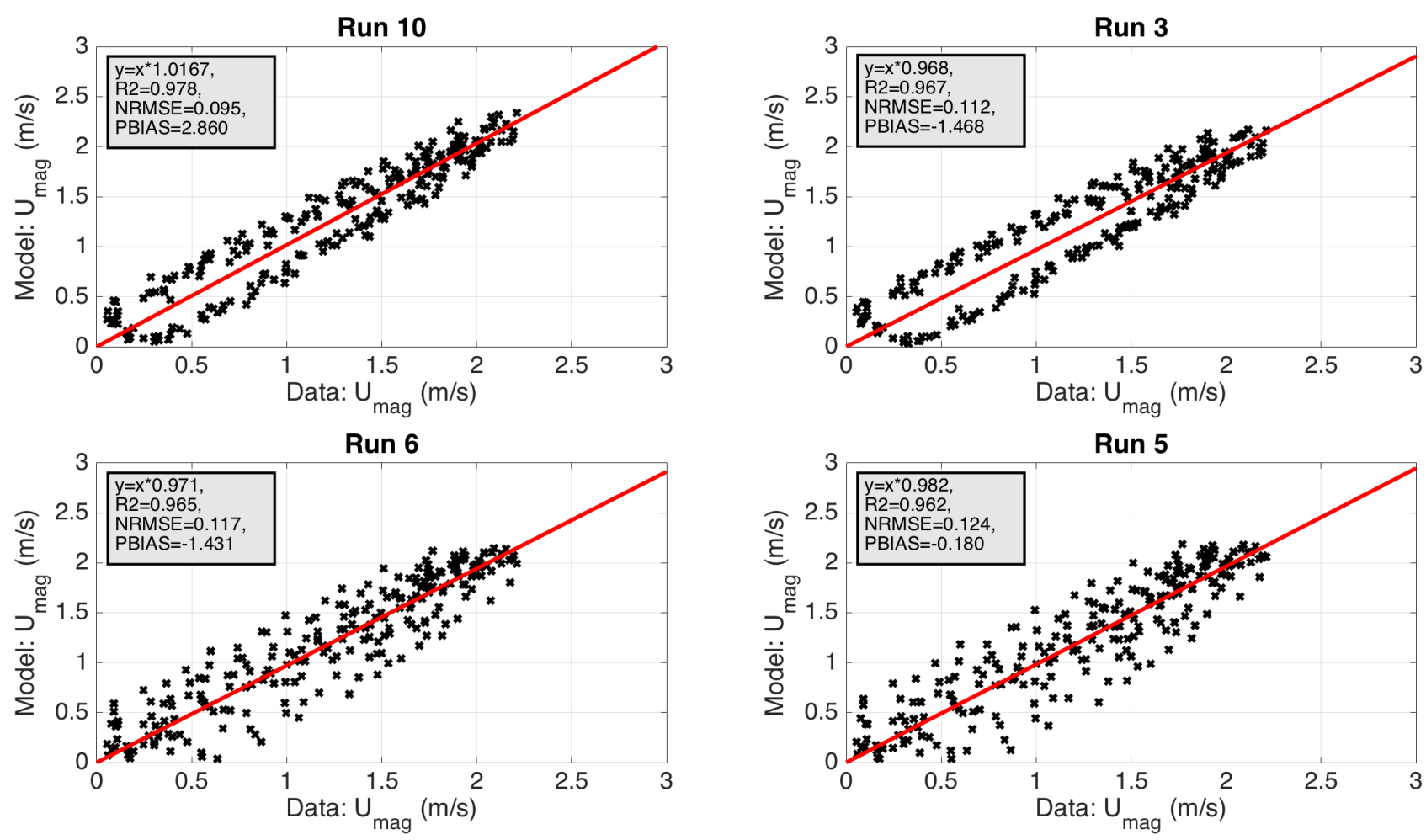

Figure 10: Scatter plots for the velocity magnitude (black crosses) at 15 metres above seabed for Run 10, Run 3, Run 6 and Run 5. In-situ data and model results are drawn along $\mathrm{x}$-axis and $\mathrm{y}$-axis, respectively.

\begin{tabular}{|l|l|l|l|l|}
\hline & Runs & NRMSE & $\mathbf{R}^{\mathbf{2}}$ & PBIAS (\%) \\
\hline $\mathbf{z}=\mathbf{2 9} \mathbf{~ m}$ & Run 3 & 0.11 & 0.97 & -0.62 \\
& Run 5 & 0.14 & 0.95 & 1.92 \\
& Run 6 & 0.12 & 0.96 & -0.41 \\
& Run 10 & 0.10 & 0.98 & 3.76 \\
\hline $\mathbf{z}=\mathbf{1 2} \mathbf{~ m}$ & Run 3 & 0.11 & 0.97 & -1.78 \\
& Run 5 & 0.12 & 0.96 & -0.44 \\
& Run 6 & 0.11 & 0.97 & -1.66 \\
& Run 10 & 0.09 & 0.98 & 2.58 \\
\hline $\mathbf{z}=\mathbf{6} \mathbf{m}$ & Run 3 & 0.10 & 0.97 & -3.79 \\
& Run 5 & 0.11 & 0.96 & -2.33 \\
& Run 6 & 0.11 & 0.96 & -3.53 \\
& Run 10 & 0.09 & 0.98 & 0.74 \\
\hline
\end{tabular}

TABLE 6: NRMSE, $\mathrm{R}^{2}$ correlation and PBIAS for velocity magnitude at different depths $(29 \mathrm{~m}, 12 \mathrm{~m}$ and $6 \mathrm{~m})$. Runs 3, 5, 6 and 10 are presented. 


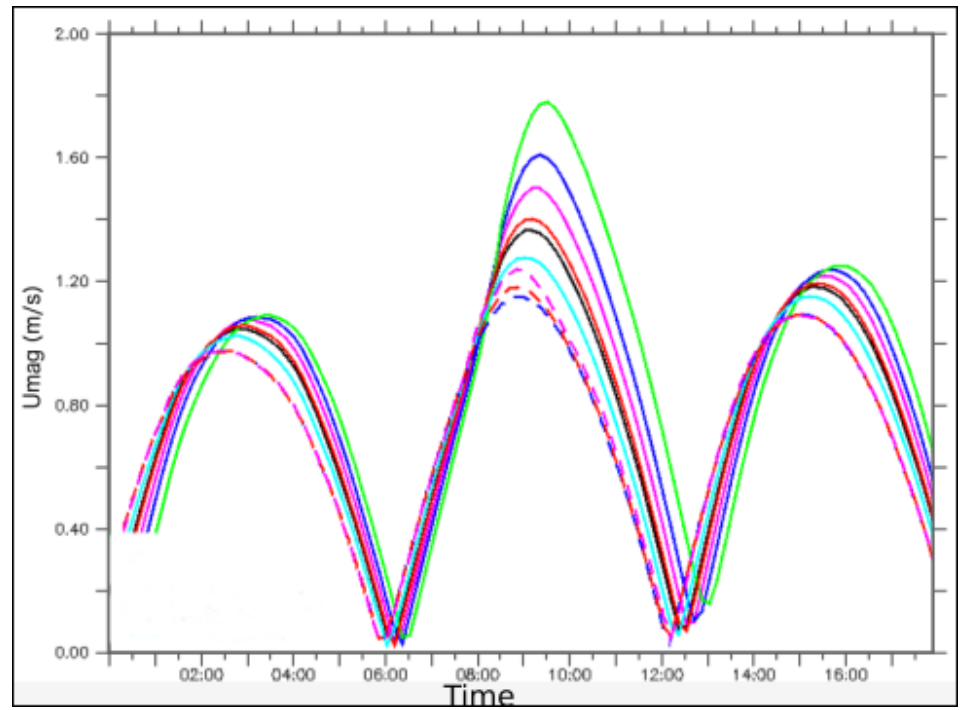

Figure 11: Time series of the velocity magnitude for different values and formulations of $z_{m}$ parameter. Simulations do not include wave effects and used a $z_{0}$ equal to $0.008 \mathrm{~m}$. Reference test was based on the quadratic formulation (black solid line). Green line is for Uchiyama et al. (2009) using $z_{m}=50 \%$ D. Other lines represent current velocity simulated with $z_{m}$ set to $26.7 \% \mathrm{D}, 11.4 \% \mathrm{D}, 5.71 \% \mathrm{D}$ and $2.67 \% \mathrm{D}$ for the solid blue, magenta, red, cyan lines. Dashed blue, red and magenta lines are for $z_{m}=1.33 \% \mathrm{D}$ and using Okubo (1971) with $f_{\text {visc }}=17, f_{\text {visc }}=10$ and Smagorinsky (1963), respectively.

\section{d. Vertical Structure of the Tidal Stream Velocity}

The vertical shape of the tidal stream velocity in Alderney Race is known to depend primarily on the tidal phase, surface wave effects, bottom friction and turbulent mixing. Thibault and Sentchev (2017) and others (e.g. Lewis et al., 2017) found that, in some particular cases, the vertical shear of the tidal sea current follows a power law (see Eq. (1) of Lewis et al., 2017) scaled with a roughness coefficient. This form fits well with their data for a calm sea. Otherwise, they showed that ocean waves, when their effects are significant, change the shear flow and increase the error between model and measurements. They recommend the use of a 3D fully wave-current model, which is what we used here. It is not easy to compare vertical profiles of the flow to observations in a location such as Alderney Race. Indeed, there are some difficult issues : i) the very rough bottom ejects intermittent 3D highly energetic turbulent eddies that modify the vertical shape of the flow, ii) the phase delay complicates the comparison : all presented plots are corrected by phase delay by adjusting the tide reversal time, iii) measurements near the surface lack precision because they have been filtered to eliminate spurious values induced by the acoustic signal reflection on the sea surface, but 
also by the air bubbles from wave breaking turbulence, and iv) ocean waves and current are orthogonal most of the time, which brings us further away from simple case where ocean waves and current directions are aligned or opposite. We need to define a scale to perform the analysis : waves and current are considered as opposite for $\left|\Delta \theta_{w / c}\right|=180^{\circ}$, aligned for $\left|\Delta \theta_{w / c}\right|=0^{\circ}$ and orthogonal for $\left|\Delta \theta_{w / c}\right|=90^{\circ}$, with $\left|\Delta \theta_{w / c}\right|$ the angle between waves and tidal current directions of propagation. Despite these issues, we compared vertical profiles to in-situ measurements.

Comparisons between model and data results were carried out at RTF1, RTF2, RTE1, RTE2, RTF3, RTF4, RTE3 and RTE4, where tidal current and wave directions differed as well as tide conditions (see Table 5). Some statistical calculations were performed for the velocity magnitude. NRSME varied from 0.02 to 0.15 , except at RTF3 where a value of 0.36 was reached in case of Run 6 . R-squared ranged from 0.96 to 0.99 except at RTF3 for Run 6 where it was around 0.92. PBIAS showed that sometimes model overestimated the measured velocity and sometimes underestimations occurred. PBIAS were less than $4 \%$, which is excellent, except for Run 6 at RTF2 and RTF3 where they were around $21 \%$. Therefore, statistical parameters showed a very good agreement $\left(R^{2} \geq 0.96, \mathrm{NRMSE} \leq 0.15\right.$, PBIAS $\leq 4 \%$ ) between in-situ measurements and model results for all runs, except for Run 6 at RTF3 and RTF2. Discrepancies for Run 6 are due to the mis-evaluation of local wind effects in the ocean model when wind blowed hard, as explained before. However, these parameters do not allow us to analyse if the vertical shapes were along the right direction.

For flood cases, at RTF1, RTF2, RTF3, wave and current directions were orthogonal while at RTF4 $\left|\Delta \theta_{w / c}\right|$ was around $80^{\circ}$. At RTF4, simulations with wave effects (Runs 3 and 6) produced higher velocity than the one without wave effects (Run 10). The wave forcing had improved the results, that were consistent with the ADCP data. Runs 6 and 3 velocities were different by their vertical structure : from 20 to $30 \mathrm{~m}$ depth above seabed, Run 6 velocity was reduced while, for Run 3, the velocity was increased. Both vertical structures being in agreement with the measurements, it is difficult to conclude. However, these forms in the upper part of the water column represent different type of wave-current interactions : aligned waves and current cause a decrease in surface flow while opposite waves and current accelerate the surface flow due to Stokes drift effects (e.g. Groeneweg and Klopman 1998). As explained previously, at RTF4, when local wind effects were included in the simulations (Run 6), the angle between waves and current tended to become small, and as a result the surface flow velocity was decreased. That what we are seen in Figure 12.

At RTF2, inappropriate boosting of the flow was visible when the wave forcing is activated, while Run 10 (without waves) fitted well to the data. The inclusion of the local wind effects in simulations had worsened the results. However, the form of the vertical profiles with wave effects (Runs 3 and 6) was good in comparison to measurements except for near 


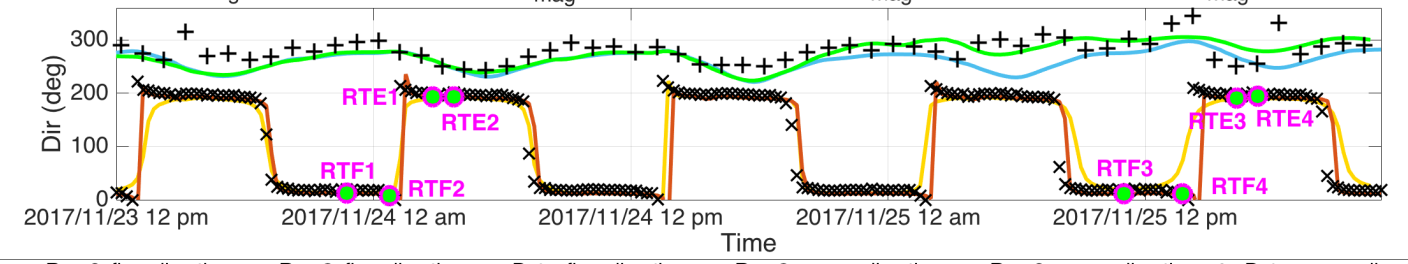
as being mis-evaluated.

For RTF1 and RTF3, the results with and without waves (Runs 3, 610 ; see Figure 12) were quite similar and fitted the ADCP data. Wave effects had little improved the results by reducing the velocity, except for Run 6 at RFT3. At these time points, as the tidal current was higher at about $1.9 \mathrm{~m} / \mathrm{s}$ at the surface (see Table 5) and the waves were small (see Figure 6a), the wave effects were overwhelmed by the tidal effects and particularly those ascribed to Stokes drift, which were in the order a few $\mathrm{cm} / \mathrm{s}$. At RTF3, as explained previously, the tidal current was abnormally reduced.

During the ebb, at RTE1, RTE2, RTE3 and RTE4, $\left|\Delta \theta_{w / c}\right|$ were less than $90^{\circ}$ and around $60^{\circ}$. For all time points, waves effects had improved the results by reducing the velocity in the upper water column due Stokes drift effects, as expected in the former studies. Nice fits with observations were obtained, particularly at RTE3 and RTE4 where waves are more energetic than at RTE1 and RTE2 (see Figure 6). Local wind effects, which had induced error during the flood on 25 November, had not worsened the vertical structure at RTE3 and RTE4.
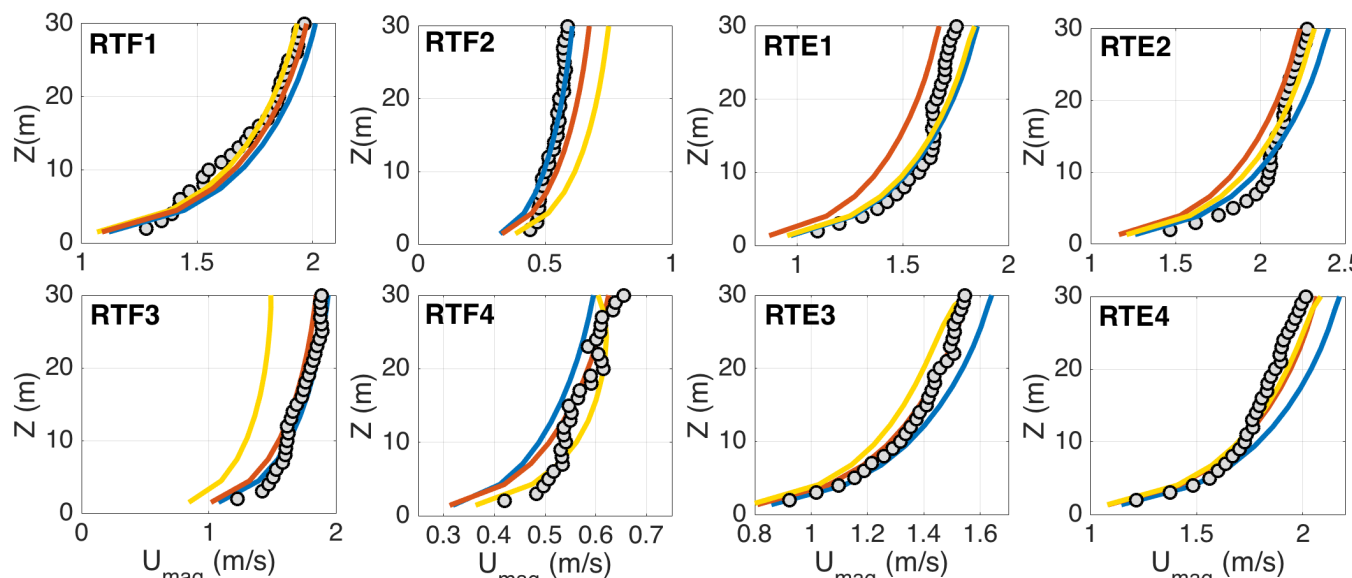

the seabed, showing that the discrepancies came from the bottom friction, which appeared

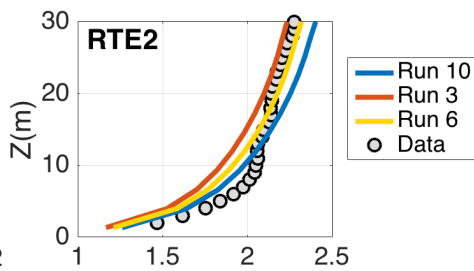

FIgURE 12: Top and middle panels : Flow velocity magnitude over depth at RTF1, RTF2, RTE1, RTE2, RTF3, RTF4, RTE3 and RTE4; in-situ measurements are in black circles while numerical results for Runs 3, 6 and 10 are in red, yellow and blue lines, respectively. Bottom panel : Time series of the flow direction for Run 3 (red line) and 6 (yellow line) and the related wave direction in light blue and green line, respectively. Measured wave and current directions are in black crosses and plusses. 


\section{Conclusions and perspectives}

The purpose of this study is twofold with a first step dealing with the validating of our modelling platform for the study site and a second step aiming to show the impacts of wave-current interactions on the hydrodynamic of the Alderney Race. To reach these goals, realistic 3D fully-coupled wave-current-turbulence simulations have been carried out and tested against in-situ measurements.

On the whole, our numerical model is successfully validated through statistical parameters (PBIAS, NRMSE, MAE, $\mathrm{R}^{2}$ ) in comparison with observations for mean sea water level, significant wave height, mean wave direction, frequency wave energy spectra, flow velocity magnitude and direction. However, a non-stationary time lag was observed sometimes between model and measurements. This problem was found to be sensitive to the waves and wind effects and had been partially fixed when these effects were included, probably due to the near-bed wave orbital velocity which changes the bottom stress. In addition, time lag was also shown as being modified by the depth where a logarithmic velocity profile is applied, highlighting the effects of the near-bed turbulence. Therefore, further studies are required to investigate what are the role in the time lag of the bottom turbulence, near-bed wave orbital velocity as well as the bathymetry effects, that drive the hydrodynamic. Furthermore, when the wind blowed hard (wind speed greater than $15 \mathrm{~m} / \mathrm{s}$ ), the flow velocity was abnormally decreased (of about $0.5 \mathrm{~m} / \mathrm{s}$ ) due to a mis-evaluating of the local wind effects in the ocean model. This point needs to be improved in the future by working on the wind stress formulation and the relating wave contribution.

Wave-current interactions were observed in Alderney Race. Ocean waves impacted the flow due to : - the Stokes drift effects, that induced an increase/decrease in the current depending on the angle between waves and current, with a maximum influence near the surface, - the wave enhancement of the bottom friction that reduced the tidal current. Furthermore, tidal current has modified ocean waves through : - the refraction of waves by the current, that have generated changes in waves directions and - the wave breaking ascribed to tidal current, that increased the turbulent mixing within the water column. The main results of this paper is the significant influence of ocean waves on the vertical profile of the flow whereas waves are small (significant wave height less than $1.5 \mathrm{~m}$ ). Moreover, changes in vertical profiles were occurred even for a strong surface current (around $2.3 \mathrm{~m} / \mathrm{s}$ ) due to the angle between waves and flow direction.

Consideration of ocean waves effects has improved the simulation of the tidal current and particularly the reproduction of its vertical shape, showing that these effects have to be taken into account for the tidal converter dimensionning. 


\section{Acknowledgments}

Authors are supported by the HYD2M project (ANR-10-IEED-0006-07) funded by the program called "Investissements d'avenir" for the building of France Energies Marines. Authors acknowledge L. Coquart, V. Garnier, M. Accensi and A. Thévenin for their technical helps. Authors are grateful to F. Ardhuin for providing the WAVEWATCH-III forcing fields. Authors thank Shom to make available their ADCP data in the framework of HYD2M. Results acquired with the Ifremer MARS software. The authors acknowledge the Pôle de Calcul et de Données Marines (PCDM) for providing CAPARMOR and DATARMOR (storage, computational resources, visualization, support services). Simulations have also benefited of the computing facilities of CRIANN. A.-C. Bennis warmly thanks P. Bousquet-Melou for his technical help during the migration step of the coupled model from CAPARMOR to CRIANN. Authors acknowledge the two anonymous reviewers for their useful comments.

\section{Références}

Agrawal, Y. C., E. A. Terray, M. A. Donelan, P. A. Hwang, A. J. Williams, W. Drennan, K. Kahma, and S. Kitaigorodskii, 1992 : Enhanced dissipation of kinetic energy beneath breaking waves. Nature, 359, 219-220.

Allen, J. I., J. T. Hold, J. Blackford, and R. Proctor, 2007a : Error quantification of a highresolution coupled hydrodynamic-ecosystem coastal-ocean model : Part 2. Chlorophyll-a, nutrients and SPM. J. Mar. Sys., 68, 381-401.

Allen, J. I., P. J. Sommerfield, and F. J. Guilbert, 2007b : Quantifying uncertainty in highresolution coupled hydrodynamic-ecosystem models. J. Mar. Sys., 64, 3-14.

Ardhuin, F., A. D. Jenkins, and K. Belibassakis, 2008a : Commentary on 'the threedimensional current and surface wave equations' by George Mellor. J. Phys. Oceanogr., 38, 1340-1349.

Ardhuin, F., W. C. O'Reilly, T. H. C. Herbers, and P. F. Jessen, 2003 : Swell transformation across the continental shelf. part I : Attenuation and directional broadening. J. Phys. Oceanogr., 33, 1921-1939.

Ardhuin, F., N. Rascle, and K. A. Belibassakis, 2008b : Explicit wave-averaged primitive equations using a generalized Lagrangian mean. Ocean Modelling, 20, 35-60.

Ardhuin, F. and A. Roland, 2012 : Coastal wave reflection, directional spread, and seismoacoustic noise sources. J. Geophys. Res., 117, C00J20. 
Ardhuin, F., N. Suzuki, J. McWilliams, and H. Aiki, 2017 : Comments on 'a combined derivation of the integrated and vertically resolved, coupled wave-current equations'. $J$. Phys. Oceanogr., 47, 2377-2385.

Ardhuin, F., et al., 2010 : Semi-empirical dissipation source functions for wind-wave models : part I, definition, calibration and validation. J. Phys. Oceanogr., 40, 1917-1941.

Ardhuin, F., et al., 2012 : Numerical wave modeling in conditions with strong currents : dissipation, refraction and relative wind. J. Phys. Oceanogr., 42, 2010-2112.

Bahaj, A. S. and L. E. Myers, 2004 : Analytical estimates of the energy yield potential from the alderney race (channel islands) using marine energy converters. Renewable Energy, 29, 1931-1945.

Bailly Du Bois, P. and F. Dumas, 2005 : Fast hydrodynamic model for medium- and longterm dispersion in seawater in the english channel and southern north sea, qualitative and quantitative validation by radionuclide tracers. Ocean Modelling, 9, 169-210.

Bailly Du Bois, P., F. Dumas, L. Solier, and C. Voiseux, 2012 : In-situ database toolbox for short-term dispersion model validation in macro-tidal seas, application for 2d-model. Continental Shelf Research, 36, 63-82.

Banihashemi, S., J. Kirby, and Z. Dong, 2017 : Approximation of wave action flux velocity in strongly sheared mean flows. Ocean Modelling, 116, 33-47.

Battjes, J. A. and J. P. F. M. Janssen, 1978 : Energy loss and set-up due to breaking of random waves. Proceedings of the 16th international conference on coastal engineering, ASCE, 569-587.

Bennis, A.-C., F. Ardhuin, and F. Dumas, 2011 : On the coupling of wave and threedimensional circulation models : Choice of theoretical framework, practical implementation and adiabatic tests. Ocean Modelling, 40, 260-272.

Bennis, A.-C., F. Ardhuin, T. Odaka, and F. Dumas, 2013 : Un nouveau modle coupl vaguescourant 3D. Paralia, 6, 8.1-8.12.

Bennis, A.-C., P. Bailly Du Bois, F. Dumas, C. Lathuillère, F. Adong, and J.-F. Filipot, 2018 : Towards a realistic numerical modelling of wave-current-turbulence interactions in Alderney Race. 2018 OCEANS - MTS/IEEE Kobe Techno-Oceans (OTO), IEEE, 1-7.

Bennis, A.-C., F. Dumas, F. Ardhuin, and B. Blanke, 2014 : Mixing parameterization : impacts on rip currents and wave set-up. Ocean Engineering, 42, 213-227. 
Bennis, A.-C., F. Dumas, and B. Blanke, 2016 : Modulation of wave-current interactions by horizontal mixing and spatial resolution. Ocean Modelling, 99, 75-85.

Boudiere, E., C. Maisondieu, F. Ardhuin, M. Accensi, L. Pineau-Guillou, and J. Lepesqueur, 2013 : A suitable metocean hindcast database for the design of marine energy converters. International Journal of Marine Energy, 3, 40-52.

Buis, S., A. Piacentini, and D. Déclat, 2008 : PALM : A computational framework for assembling high performance computing applications. Concurrency Computat. : Pract. Exper., 18 (2), 247-262.

Burchard, H., 2001 : Simulating the wave-enhanced layer under breaking surface waves with two-equation turbulence models. J. Phys. Oceanogr., 31, 3133-3145.

Christoffersen, J. B. and I. G. Jonsson, 1985 : Bed friction and dissipation in a combined current and wave motion. Ocean Eng., 12 (5), 387-423.

Coelingh, J., A. V. Wijk, and A. Holtslag, 1996 : Analysis of wind speed observations over the North Sea. Journal of Wind Engineering and Industrial Aerodynamics, 61, 51-69.

Coelingh, J., A. V. Wijk, and A. Holtslag, 1998 : Analysis of wind speed observations over the North Sea. Journal of Wind Engineering and Industrial Aerodynamics, 73, 125-144.

Coles, D. S., L. S. Blunden, and A. S., 2017 : Assessment of the energy extraction potential at tidal sites around the channel islands. Energy, 124, 171-186.

Craik, A. D. D. and S. Leibovich, 1976 : A rational model for Langmuir circulations. J. Fluid Mech., 73, 401-426.

Dauvin, J.-C., 2015 : History of benthic research in the english channel : From general patterns of communities to habitat mosaic description. Journal of Sea Research, 100, $32-45$.

Delpey, M., F. Ardhuin, P. Otheguy, and A. Jouon, 2014 : Effects of waves on coastal water dispersion in a small estuarine bay. J. Geophys. Res., 119, 70-86.

Donelan, M. A., J. Hamilton, and W. H. Hui, 1985 : Directional spectra of wind-generated waves. Phil. Trans. Roy. Soc. London A, 315, 509-562.

Filipot, J.-F. and F. Ardhuin, 2012 : A unified spectral parameterization for wave breaking : from the deep ocean to the surf zone. J. Geophys. Res., 115, C04022. 
Foveau, A., S. Haquin, and J. Dauvin, 2017 : Using underwater imagery as a complementary tool for benthos sampling in an area with high-energy hydrodynamic conditions. Journal of Marine Biology Oceanography, 6, 1-7.

Furgerot, L., P. Bailly Du Bois, Y. Méar, E. Poizot, and A.-C. Bennis, 2018 : Velocity profile variability at a tidal-stream energy site (aldemey race, france) : From short (second) to yearly time scales. 2018 OCEANS - MTS/IEEE Kobe Techno-Oceans (OTO), IEEE, 1-8.

Furgerot, L., Y. Poprawski, M. Violet, E. Poizot, P. Bailly Du Bois, M. Morillon, and Y. Mear, 2019 : Mobile vs encrusted quaternary sediments and their bedrock in a tidedominated environment (Alderney Race). Journal of Maps, 1-19.

Grant, W. D. and O. S. Madsen, 1979 : Combined wave and current interaction with a rough bottom. J. Geophys. Res., 84, 1797-1808.

Groeneweg, J. and G. Klopman, 1998 : Changes in the mean velocity profiles in the combined wave-current motion described in GLM formulation. J. Fluid Mech., 370, 271-296.

Guillou, N., G. Chapalain, and S. P. Neill, 2016 : The influence of waves on the tidal kinetic energy site. Applied Energy, 180, 402-415.

Hashemi, M., S. Neill, P. Robins, A. Davies, and M. Lewis, 2015 : Effects of waves on the tidal energy resource at a planned tidal stream array. Renewable Energy, 75, 626-639.

Hasselmann, K., et al., 1973 : Measurements of wind-wave growth and swell decay during the Joint North Sea Wave Project. Deut. Hydrogr. Z., 8 (12), 1-95, suppl. A.

Hasselmann, S., K. Hasselmann, J. Allender, and T. Barnett, 1985 : Computation and parameterizations of the nonlinear energy transfer in a gravity-wave spectrum. Part II : Parameterizations of the nonlinear energy transfer for application in wave models. J. Phys. Oceanogr., 15, 1378-1391, URL http://ams.allenpress.com/archive/1520-0485/15/ 11/pdf/i1520-0485-15-11-1378.pdf.

Holmedal, L. E., D. Myrhaug, and H. Rue, 2000 : Seabed shear stresses under irregular waves plus current from monte carlo simulations of parameterized models. Coastal Eng., 39, 123-147.

Kantha, L. H. and C. A. Clayson, 2004 : On the effect of surface gravity waves on mixing in the oceanic mixed layer. Ocean Modelling, 6, 101-124.

Kemp, P. H. and R. R. Simons, 1982 : The interaction of waves and a turbulent current : waves propagating with the current. J. Fluid Mech., 116, 227-250. 
Kemp, P. H. and R. R. Simons, 1983 : The interaction of waves and a turbulent current : waves propagating against the current. J. Fluid Mech., 130, 73-89.

Kumar, N., G. Voulgaris, J. C. Warner, and M. Olabarrieta, 2012 : Implementation of the vortex force formalism in the coupled ocean-atmosphere-wave-sediment transport (COAWST) modeling system for inner shelf and surf zone applications. Ocean Modelling, 47, 65-95.

Larsonneur, C., P. Bouysse, and J.-P. Auffret, 1982 : The superficial sediments of the english channel and its western approaches sedimentology. Sedimentology, 851-864.

Lazure, P. and F. Dumas, 2008 : An external-internal mode coupling for a 3d hydrodynamical model for applications at regional scale (MARS). Adv. Water Resources, 31, 233-250.

Leroy, R. and B. Simon, 2003 : Réalisation et validation d'un modèle de marée en Manche et dans le golfe de Gascogne - Application à la réalisation d'un nouveau programme de réduction de sondages bathymétriques.

Lewis, M., S. Neill, P. Robins, M. Hashemi, and S. Ward, 2017 : Characteristics of the velocity profile at tidal-stream energy sites. Renewable Energy, 1-15.

Lewis, M. J., S. P. Neill, M. R. Hashemi, and M. Reza, 2014 : Realistic wave conditions and their influence on the quantifying the tidal stream energy resource. Applied Energy, 136, $495-508$.

Lewis, M. J., S. P. Neill, P. E. Robins, and M. R. Hashemi, 2015 : Resource assessment for future generations of tidal-stream energy arrays. Energy, 83, 403-415.

Lopez, G., et al., 2018 : Hydrodynamics of the alderney race : HF radar wave measurements. Proceeding of the International Conference on Ocean Energy, France, 1-6.

Lopez, G., et al., 2019 : Surface hydrodynamics of the alderney race from HF radar measurements. Proceeding of the 13th European Wave and Tidal Energy Conference, Italy, $1-10$.

Lynn, P. A., 2013 : Electricity from Wave and Tide : An Introduction to Marine Energy. John Wiley and Sons Ltd, 276 pp.

Maisondieu, C., 2016 : Statistical characterization of complex sea-states in the bay of Biscay for the design of marine structures. Proceedings of the 15th Journées de l'Hydrohydynamique, November 22-24, Brest, France, 1-12. 
Marechal, D., 2004 : A soil-based approach to rainfall-runoff modelling in un- gauged catchments for england and wales. Ph.D. thesis, University of Cranfield, UK.

Mathisen, P. P. and O. S. Madsen, 1996a : Wave and currents over a fixed rippled bed. 2. bottom and apparent roughness experienced by currents in the presence of waves. $J$. Geophys. Res., 101 (C7), 16,543-16,550.

Mathisen, P. P. and O. S. Madsen, 1996b : Waves and currents over a fixed rippled bed. 1 . bottom roughness experienced by waves in the presence and absence of currents. $J$. Geophys. Res., 101 (C7), 16,533-16,542.

Mathisen, P. P. and O. S. Madsen, 1999 : Wave and currents over a fixed rippled bed. 3. bottom and apparent roughness for spectral waves and currents. J. Geophys. Res., 104 (C8), 18,447-18,461.

McWilliams, J. C., J. M. Restrepo, and E. M. Lane, 2004 : An asymptotic theory for the interaction of waves and currents in coastal waters. J. Fluid Mech., 511, 135-178.

Mellor, G., 2015 : A combined derivation of the integrated and vertically resolved, coupled wave-current equations. J. Phys. Oceanogr., 45, 1453-1463.

Mellor, G., 2017 : Reply to comments on 'a combined derivation of the integrated and vertically resolved, coupled wave-current equations'. J. Phys. Oceanogr., 47, 2387-2389.

Mercier, P., 2019 : Modlisation de la turbulence engendre par la bathymtrie dans le raz blanchard : Approche locale (lbm-les). Ph.D. thesis, Caen University, France.

Michaud, H., P. Marsaleix, C. Estournel, F. Bourrin, F. Lyard, C. Mayet, and F. Ardhuin, 2012 : Three-dimensional modelling of wave-induced current from the surf zone to the inner shelf. Ocean Science, 8, 657-681.

Moghimi, S., K. Klingbeil, U. Grawe, and H. Burchard, 2013 : A direct comparison of the depth-dependent radiation stress method and a vortex force formulation within a threedimensional ocean model. Ocean Modelling, 70, 132-144.

Nielsen, P., 1992 : Coastal bottom boudary layers and sediment transport. World Scientific Publishing.

Okubo, A., 1971 : Oceanic diffusion diagram. Deep Sea Research, 18, 789-802.

Phillips, O. M., 1958 : The equilibrium range in the spectrum of wind-generated waves. $J$. Fluid Mech., 4, 426-433. 
Shom, 2017 : Références altimétriques maritimes. URL https://www.data.gouv.fr/fr/ datasets/references-altimetriques-maritimes/, ISBN 978-2-11-139469-8.

Signell, R. P., R. C. Beardsley, H. C. Graber, and C. Capotondi, 1990 : Effect of wave-current interation on wind-driven circulation in narrow, shallow embayments. J. Geophys. Res., 95 (C6), 9671-9678.

Sleath, J. F. A., 1991 : Velocities and shear stresses in wave-current flows. J. Geophys. Res., 96 (C8), $15237-15244$.

Smagorinsky, J., 1963 : General circulations experiments with the primitive equations i. the basic experiment. Monthly Weather Review, 8, 99-165.

Soulsby, R. L., 1995 : Bed shear stresses due to combined waves and currents. In : Stive, M., Fredsøe, J., Hamm, L., Soulsby, R., Teisson, C., Winterwerp, J. (Eds). Advances in Coastal Morphodynamics, Delft Hydraulics, Delft, The Netherlands, 420-423.

Soulsby, R. L., L. Hamm, G. Klopman, D. Myrhaug, R. R. Simons, and G. P. Thomas, 1993 : Wave-current interaction within and outside the bottom boudary layer. Coastal Eng., 21, 41-69.

Thiebault, M. and A. Sentchev, 2017 : Asymmetry of tidal currents off W. Brittany coast and assessment of tidal energy resource around ushant island. Renewable Energy, 105, $735-747$.

Thiebault, M., A. Sentchev, and P. Bailly-Du-Bois, 2019 : Merging velocity measurements and modeling to improve understanding of tidal stream resource in alderney race. Energy, 178, 460-470.

Thiebot, J., P. B. du Bois, and S. Guillou, 2015 : Numerical modeling of the effect of tidal stream turbines on the hydrodynamics and the sediment transport : Application to the Alderney Race (Raz Blanchard), France. Renewable Energy, 75, 356 - 365.

Toba, Y., 1973 : Local balance in the air-sea boundary processes. II partition of wind stress to waves and current. J. Oceanogr. Soc. Japan, 29, 70-75, URL http://www.terrapub. co.jp/journals/JO/JOSJ/pdf/2902/29020070.pdf.

Togneri, M., M. Lewis, S. Neill, and I. Masters, 2017 : Comparison of ADCP measurements and 3D model simulations of turbulence at a tidal energy site. Renewable Energy, 1-10.

Tolman, H. L. and al., 2014 : User manual and system documentation of WAVEWATCHIII $^{\mathrm{TM}}$ version 4.18. Tech. Rep. 282, NOAA/NWS/NCEP/MMAB. 
Uchiyama, Y., J. C. McWilliams, and J. M. Restrepo, 2009 : Wave-current interaction in nearshore shear instability analyzed with a vortex force formalism. J. Geophys. Res., 114.

Uchiyama, Y., J. C. McWilliams, and A. F. Shchepetkin, 2010 : Wave-current interaction in oceanic circulation model with a vortex-force formalism Application to the surf zone. Ocean Modelling, 34, 16-35.

Valcke, S., T. Craig, and L. Coquart, 2015 : OASIS3-MCT User Guide. Tech. rep., CERFACS.

Walstra, D. J. R., J. Roelvink, and J. Groeneweg, 2000 : Calculation of wave-driven currents in a 3D mean flow model. Proceedings of the 27th International Conference on Coastal Engineering, Sydney, ASCE, Vol. 2, 1050-1063.

Warner, J., B. Armstrong, R. He, and J. Zambon, 2010 : Development of a coupled oceanatmosphere-wave-sediment transport (COAWST) modeling system. Ocean Modelling, 35, 230-244.

Warner, J. C., C. R. Sherwood, H. G. Arengo, and R. P. Signell, 2005 : Performance of four turbulence models implemented using a generic length scale method. Ocean Modelling, 8, $81-113$.

Wolf, J. and D. Prandle, 1999 : Some observations of wave-current interaction. Coastal Eng., 37, 471-485.

Xie, L., K. Wu, L. Pietrafesa, and C. Zhang, 2001 : A numerical study of wave-current interactions through surface and bottom stresses: wind-driven circulation in the South Atlantic Bight under uniform winds. J. Geophys. Res., 106 (C8), 16 841-16855.

Zhang, H., O. S. Madsen, S. A. Sannasiry, and E. S. Chan, 2004 : Hydrodynamic model with wave-current interaction in coastal regions. Estuarine, Coastal and Shelf Science, 61, $317-324$.

Zieger, S., A. V. Babanin, W. E. Rogers, and I. R. Young, 2015 : Observation- based source terms in the third-generation wave model wavewatch. Ocean Modelling, 96, 2-25. 